NBER WORKING PAPER SERIES

\title{
CONTEMPORARY STATE POLICIES AND INTERGENERATIONAL INCOME MOBILITY
}

Lars J. Lefgren

Jaren C. Pope

David P. Sims

Working Paper 25896

http://www.nber.org/papers/w25896

\author{
NATIONAL BUREAU OF ECONOMIC RESEARCH \\ 1050 Massachusetts Avenue \\ Cambridge, MA 02138
}

May 2019

We would like to thank Samuel Higbee for superlative research assistance. We thank the BYU College of Family, Home, and Social Science for generous research support. We thank seminar participants at Aalto University for helpful feedback. The views expressed herein are those of the authors and do not necessarily reflect the views of the National Bureau of Economic Research.

NBER working papers are circulated for discussion and comment purposes. They have not been peer-reviewed or been subject to the review by the NBER Board of Directors that accompanies official NBER publications.

(C) 2019 by Lars J. Lefgren, Jaren C. Pope, and David P. Sims. All rights reserved. Short sections of text, not to exceed two paragraphs, may be quoted without explicit permission provided that full credit, including $\odot$ notice, is given to the source. 
Contemporary State Policies and Intergenerational Income Mobility

Lars J. Lefgren, Jaren C. Pope, and David P. Sims

NBER Working Paper No. 25896

May 2019

JEL No. I3,J0

\begin{abstract}
$\underline{\text { ABSTRACT }}$
Using county-level analysis, this study demonstrates that there exists at most a minor relationship between the large, contemporary geographical variation in U.S. intergenerational income mobility and state-level policies. In addition to investigating the effects of specific policies, we introduce an omnibus test for state policy differences in total, based on the principle of geographic discontinuities. We further explore the discrepancy between these findings and the expected efficacy of mobility-enhancing policies seen in common applied economic models and successful program evaluations. We conclude that the gap between quasi-experimental evaluations and observed policy effects presents pressing questions for further study.
\end{abstract}

Lars J. Lefgren

Department of Economics

Brigham Young University

130 Faculty Office Building

Provo, UT 84602

and NBER

lars_lefgren@byu.edu

Jaren C. Pope

Department of Economics

130 Faculty Office Building

Brigham Young University

Provo, UT 84602

jaren_pope@byu.edu
David P. Sims

130 Faculty Office Building

Brigham Young University

Provo, UT 84602-2363

davesims@byu.edu 


\section{Introduction}

The level of contemporary economic mobility is a concern among economists, the policy community, and the public more generally. Many Americans consider intergenerational economic mobility, the ability to change our economic fortunes from those experienced by our parents, to be an important element of the American Dream and to be a more important policy target than point-in-time economic inequality (Pew 2011, 2012). This urgency is perhaps due to the increasing body of evidence that the U.S. has relatively low economic mobility when compared to other developed countries (Corak 2006; Jantii et al 2006; Blanden 2009).

However, this low average level of economic mobility masks important contemporary geographical variation within the U.S. In other words, there is substantial evidence of large, persistent differences in intergenerational mobility across U.S. commuting areas (Chetty, Hendren, et al. (2014a); Chetty, Hendren, et al. 2014c). This translates into considerable differences in the economic mobility of people in different States, ranging from a rank-rank correlation of incomes across generations of 0.23 in Hawaii to 0.42 in Mississippi.

Notably, there are also large differences in the degree to which American States have adopted the sorts of policies economists expect to increase mobility. These expectations are rooted in past theoretical and empirical research. In the first case, the literature contains multiple economic models that predict policy-induced mobility. Candidate policies include more progressive levels of public educational investments (Solon, 2004), differences in institutional political design (Ichino, Karabarbounis, et al., 2011), and differences in tax rates (Lefgren, McIntyre, et al., 2015). 
In the empirical literature, some of the most noted program evaluations find positive effects of specific government policies on the educational and labor market outcomes of disadvantaged children. For example, Garces, Thomas, and Currie (2002) find that the Head Start preschool program increased the eventual educational attainment of low-income white children. Chetty et al. (2011) find that smaller kindergarten classes lead to higher eventual educational attainment. Dahl and Lochner (2012) find that increases in family income due to changes in the Earned Income Tax Credit increase child test scores. These are merely some of the studies that suggest that a range of government interventions can improve cognition, behavior, and even adult earnings for some disadvantaged children. Furthermore, some studies of past U.S. history, such as Card and Krueger (1992) suggest early $20^{\text {th }}$ century state education policies had important effects on economic mobility.

Due to these previous studies, it seems intuitive that much of the geographic variation in economic mobility should be explained by the degree to which states, the key actors in these sorts of choices, have adopted such policies. In this paper we show that it is, in fact, surprisingly difficult to find statistical evidence that state-level policies have a meaningful amount of explanatory power for the contemporary patterns of economic mobility in the U.S. These results lead naturally to an inquiry about why such a discrepancy exists between the quasi-experimental results on program evaluation and the measurable effects of state policies.

We begin by deriving a cross sectional test of the effects of some specific, hypothesized state policies on contemporary economic mobility in the United States. Underlying this approach is the idea that if state-level policies are an important source of geographic differences in intergenerational mobility, we would expect to see discontinuous differences in levels of intergenerational mobility as we cross state borders. Thus, we hope to make comparisons among 
populations exposed to different polices that have similar cultural elements and other unobservable determinants of income mobility. This methodology expands on previous studies used to detect the effects of cross-state policy variation on manufacturing viability (Holmes, 1998), the effects of minimum wage policies on employment and earnings (Dube, Lester, et al., 2010), and the attained level of schooling of southern children in the 1930's (Card et al 2018). The results of these tests suggest that neither state public education investments, state investments in broader social welfare spending, nor tax rate differences have more than small effects on income mobility.

Since these results may be subject to error arising from either mismeasurement of state policy variables or omission of other state level policies that might be alternative mechanisms for generating observed geographic patterns of income mobility, we then develop an omnibus test for the effect of the entire observed portfolio of state policy differences on mobility. We find that the observed pattern of state-level policy differences provides a poor explanation for the contemporary geographical differences in income mobility. In particular, we find no discernable differences in income mobility from moving across state lines as opposed to county lines within a state, even when we choose the sample to focus on adjacent states with the largest average mobility differences.

Finally, we confront the obvious puzzle: If program evaluations suggest that state economic policy decisions can be effective in improving economic fortunes for the poor at a micro-level, why is it so hard to detect any aggregate mobility effects from state-level policies? We consider several possibilities, including estimation biases from measurement error or geographic mobility, unintended consequences of policy scaling, and explanations rooted in the political economy of policy choice and execution. While a definitive, quantitative answer to this 
question is beyond the scope of our inquiry, this paper highlights the need to investigate this discrepancy and suggests some possible avenues for future inquiry

The remainder of the paper proceeds as follows. Section 2 provides more background information about state policies and economic mobility, most notably from the previous literature. Section 3 discusses the data used in the paper. Section 4 motivates and presents our baseline methodology and results. Section 5 develops and implements the omnibus test of state policies that may be linked to inequality. In section 6 we discuss possible ways to reconcile our results with the cross-sectional program evaluation literature, while providing a number of robustness tests that address potential explanations. Section 7 concludes the paper.

\section{Economic Mobility and Public Policy}

The introduction provided notable examples of program evaluations that use quasiexperimental methods to find positive "micro" effects of potential policy choices on the future educational and labor market outcomes of poor children. These program evaluation results exist for multiple types of policies, such as pre-school and school educational interventions, school funding increases, and targeted social welfare programs. These programs, however, are usually small in scale or experimental in nature.

In contrast, relatively few papers examine the statistical link between actual state-level policies and levels of economic mobility. These studies do suggest that state policies toward education may have played an important part in determining historical levels of economic mobility in the American South. The most important work in this literature, Card and Krueger (1992), finds that very large increases in the state provision of educational resources in the mid- 
$20^{\text {th }}$ century American South, especially to black children, played an important role in the subsequent 15 percentage point decrease in the black white wage gap from 1960-1980. Although the authors do not directly link this episode to mobility measures, the relative disparities between racial group incomes at the time almost guarantee such income movements reflect expanded economic mobility. Mayer and Lopoo (2008), who examine the relationship between state level educational spending and income mobility for a group of children born between 1956 and 1970, further support such a link. They find a positive effect of growing up in a high spending state on mobility. Examining their specifications shows their effect is largely driven by the southern states.

In a sense, these findings make the present study more important. If past differences in state policies related to educational resources played a large role in geographic differences in economic mobility, it remains important to know if the same pattern is true today. Indeed, there are reasons to believe that the relationship might be quantitatively different, and that these magnitudes may be particular to the educational reforms that attended the end of the Jim Crow regime. It is well known, for example, that despite continued increases in real school funding levels in the 1980s and 1990's, the convergence in the black-white wage gap effectively ceased after 1980 (Bayer \& Charles 2016).

Furthermore, recent studies fail to find similar effects attributable to differences in current education policies. For example, Rothstein (2019) concludes that only a small proportion of mobility differences can be explained by any features of the education system, while Grawe (2010), which places less weight on the variation provided by the southern states, concludes that U.S. states with smaller class sizes actually experience less mobility. 
The small number of studies of this type is likely due to the difficulty of convincingly identifying the impacts of state policies on intergenerational economic mobility. Longitudinal comparisons require variation in policies that could plausibly drive economic mobility as well as longitudinal estimates of economic mobility itself. Identification is further complicated by the fact that even a sharp change in policies will typically have only a gradual effect on mobility as the duration of treatment increases smoothly with cohort age.

While cross-sectional estimates have the advantage of relying on stable policy differences that create variation in the duration of treatment across populations, they are always open to concerns about bias arising from the omission of relevant factors from the regressions. It seems likely that places with different policies may also have different populations. In particular, to the extent that pro-mobility policies occur in areas with a culture or population that has unobservable characteristics that promote income mobility, the observed impact of such polices will be overstated. The converse would be true if pro-mobility policies occur in areas with unobservable barriers to mobility. Comparing locations that are spatially and culturally distant likely exacerbates these problems. Given a method to construct a plausible control group, however, the cross sectional approach might be favored due to the extreme difficulty of constructing consistent measures of state-level mobility over multiple generations.

\section{Data}

This paper brings together county and state-level data from a variety of sources. As a measure of intergenerational mobility we use the county level rank-rank slope as calculated for the 1980-1982 child birth cohorts by the Equality of Opportunity Project (Chetty, Hendren, et al., 
2014b). ${ }^{1}$ This is the estimated slope coefficient from a regression of child income percentile rank (within their county) on their parents' percentile rank. While this measure ignores changes in the variance of the income distribution over time, it is preferable to the slope coefficient of child income on parents' income because of its robustness across specifications and cross-region comparability (Chetty, Hendren, et al., 2014a). Additionally, the results are quite similar if we instead use the expected percentile rank of children whose parents are at the $25^{\text {th }}$ percentile of the national income distribution, a measure of absolute upward mobility. ${ }^{2}$

The Equality of Opportunity Project dataset also includes county level demographic measures, derived from census data, including the fraction of live births in the county with teenage mothers, the fraction of county families considered middle class, that is between the $25^{\text {th }}$ and $75^{\text {th }}$ percentile of the national income distribution, and various centile points of the county family income distribution.

In order to test specific state-level policies, we have assembled detailed data on a number of plausible candidates. Data on per-pupil educational expenditure comes from the National Center of Education Statistics (NCES) Longitudinal Fiscal-Non-Fiscal data file. From this file we take the district revenue data for all school years starting from 1990 to 1995. These years

\footnotetext{
${ }^{1}$ While this is certainly the best measure of U.S. intergenerational income mobility at a fine geographic scale ever produced, it is not without some limitations. The tax data that Chetty et al. use to create their intergenerational mobility measure is based on tax information that only goes back to 1996. This means that it can only use certain parts of the earnings lifecycle for parents and children which can lead to some bias in the estimates. Recent work by Mazumder (2015) suggests that this can lead to some bias in the intergenerational elasticity estimates, but very little bias in the measure we use, the rank-rank slope.

${ }^{2}$ In their later paper Chetty, Hendren et al. (2015) compute quasi-experimental county level estimates that they refer to as the causal effects of being raised in that county on upward mobility. We choose not to use those estimates for our county-level mobility measure because they are produced by Bayesian shrinkage to covariate predictions. As a result, the causal estimates for counties with fewer household observations (such as our border counties) are largely reflective of covariates which tend to be similar across adjacent states. Thus, using such estimates would bias us toward a conclusion of no state policy effects based on variation that is explicitly not policy induced. One could use the raw measures of mobility that are not shrunken. However, these tend to be computed on extremely small sample sizes for most border counties.
} 
correspond to when the children in the sample were 8-15 years old. Using this data, which breaks down school district revenues by source, we have computed a per-pupil measure of state and local source funding as well as a measure of total per-pupil funding. We match this at the district level to demographic information from the NCES common core of data for the same years.

We then assign school districts to counties based on the headquarters location of the district and use the NCES measure of district enrollments to produce a pupil-weighted average funding measure for each county for the 1990-1995 school years. We also obtain county level teacher and pupil counts for that same year and use them to produce a county pupil-teacher ratio. We begin with the 1990-1991 school year because it was the earliest year in which the NCES fiscal data covered the universe of districts, as opposed to a sample, in all states, and because it corresponds to a time when our mobility cohort is in elementary school.

We use information on state taxes for representative taxpayers provided by the TAXSIM generated tables maintained by the National Bureau of Economic Research (Feenberg and Coutts, 1993). ${ }^{3}$ These data show marginal tax rates for households with $\$ 10,000, \$ 50,000$, and $\$ 100,000$ in adjusted gross income, measured in 2005 dollars. We refer to these categories as low, medium, and high income households. The tax rates are measured in decimals so a tax rate of 0.1 represents a marginal tax rate of 10 percent. Since we are interested in the relationship among incomes across generations, both the tax rates faced by parents early in a child's life, and the tax rates faced by the child as she becomes an adult could be important income determinants. Consequently, we average the calculated rates between 1985 and 2010, which spans the lives of the children in our sample.

\footnotetext{
3 The tables can be obtained at http://users.nber.org/ taxsim/state-tax-tables/ They were accessed on 6/2/2014.
} 
To obtain a measure of the relative generosity of various state social-safety nets in this time period, we use the March Current Population Survey (CPS) from the years 1988-92. These years were chosen to be in the middle of the childhood of the cohort for whom we have mobility measurements and to represent a time period in which the CPS questions on the receipt of public assistance were constant. Using this data we compute the average amount of assistance received by households in poverty with at least one child present in each state-year from a combination of heating assistance, food stamps. Unemployment Insurance, Workers Compensation benefits, Supplemental Security Income, and cash welfare programs such as AFDC, in other words programs considered in the CPS for which benefit rules can vary due to state policy.

Descriptive statistics are given in Table 1. In specifications in which we control for observable county-level characteristics, we include all demographic and income variables listed in the table. The first column of the table treats the county as the unit of observation, while the second considers states as whole entities. For either unit, the table reveals the wide variability of state mobility levels and policies. The average county has a parent child income rank correlation of 0.33 with a standard deviation of 0.07 . When constructing our tables, we multiply this mobility measure by 100 in order to eliminate leading zeroes. This high variance can also be seen in contemporary inequality measures for the parents' generation, as the standard deviation of the Gini coefficient is 0.09 across counties and 0.08 across states. By way of comparison, the standard deviation of the 2010 Gini coefficients for the 26 OECD countries that report a figure is 0.04. ${ }^{4}$ Examining state polices shows that the standard deviation of non-federal education spending is nearly $\$ 1,700$ per-pupil and that for the high and medium tax scenarios the standard

\footnotetext{
${ }^{4}$ The OECD Gini numbers can be found at http://stats.oecd.org/ and were accessed on June 10, 2014.
} 
deviation of marginal rates is more than half the mean. There is also substantial variation in the generosity of state-level transfer payments

Finally, in order to check for potentially confounding effects of migration we collected county-to-county migration data for 2004 and 2005 from the Statistics of Income (SOI) division of the Internal Revenue Service (IRS). Using records of all individual income tax forms filed each year, the SOI is able to track year-to-year individual migration in the United States in a systematic way. Since this data is obtained from tax records, they are the most reliable, comprehensive, and widely used source of migration data in the U.S. It is believed that the data captures about $95-98 \%$ of the migration of tax filers and their households in the United States (Gross, 2005). ${ }^{5}$

\section{The impact of specific state policies on intergenerational mobility}

In this section, we motivate and detail our baseline empirical approach, then present its results. As previously mentioned, there are simple, theoretical models of intergenerational income transmission that provide insights regarding how state policies could generate differences in intergenerational income mobility. Building on the work of Becker and Tomes (1979), Solon (2004) describes how progressive government investments in education can overcome credit market failures that prevent low income parents from making efficient human capital

\footnotetext{
${ }^{5}$ While this is considered the best available migration data available, the data has some well-known limitations. For example, since the data is based on income tax returns, if a household is not required to file a tax return they will not be represented in the data. Thus the data tends to underrepresent the very poor and the elderly who may not be required to file tax returns. Also, late filers (who tend to be very wealthy) that were granted a filing extension past late September are excluded. Thus the data also tends to underrepresent the very wealthy. Finally, the publicly available data does not provide the demographics of the migrants. For additional discussion on these and other issues with the data see Gross (2005).
} 
investments for their children. Similarly, other social welfare policies which increase the incomes of poor parents, may also increase intergenerational mobility if such policies relax budget constraints that prevent parents from investing in their children. Furthermore, other models, such as Ichino, Karabarbounis et al. (2011) focus on differences in political institutions, which are understood to produce the variation in education policies that drives differences in economic mobility. Nor is public social spending the only potential source of relevant policy differences. Lefgren, McIntyre, et al. (2015) discuss how labor market distortions, including wage taxation, can decrease intergenerational income mobility by limiting the correlation between human capital and income.

These mechanisms might also help to explain the large amount of geographic variation in income mobility in the United States. Figure 1 provides a map depicting county level mobility rates in the United States taken from data assembled by Chetty, Hendren, et al. (2014b). State borders are indicated in bold and white areas indicate counties where there is no mobility data. The darkest shaded areas represent the quintile of counties with the least amount of upward mobility while the lightest shaded areas have the most upward mobility. For enhanced visibility, Figure 2 focuses more tightly on a central region of the United States, which was selected due to its many state borders. Here we see substantial variation in mobility within a small group of states. Furthermore, a casual inspection suggests that moving from the lighter to darker areas (higher to lower mobility) seems as likely to happen within a given state as when crossing state borders. Though this informal inspection is not definitive, the lack of visual evidence of clear state-level patterns is a good starting point to motivate a discussion about a more formal methodology. 


\subsection{Statistical Model}

To understand how we propose to find evidence for state-level policy impacts on economic mobility, it is helpful to consider a simple statistical model. The model also clarifies the potential limitations of our methods. Intuitively, we wish to compare mobility rates between adjacent counties across state borders. Our assumption is that such counties will be sufficiently similar that we can isolate the impact of differing state policies. Suppose that intergenerational mobility within a county is determined by the following equation:

(1) $M_{i s}=X_{i s} \beta+D_{s} \alpha+\epsilon_{i s}$.

In this model, intergenerational mobility in county $i$ and state $s$ is indicated by $M_{i s}$. Furthermore, mobility is a linear function of county-level observable characteristics, $X_{i s}$, a particular, measurable policy variable, or vector of state-level policy variables $D_{s}$, and an error term, $\epsilon_{i s}$, which includes unobservable county-level factors driving mobility as well as measurement error.

In a standard cross-sectional setting, we worry that $D_{s}$ may be correlated with $\epsilon_{i s}$. This would be true if cultural or economic phenomena that drove mobility were also correlated with the policies under examination. For example, ethnic homogeneity of the population may reduce social distance between the rich and poor, increasing intergenerational economic mobility, while at the same time leading voters to favor greater redistribution.

To mitigate such bias, we estimate the following equation:

(2) $M_{i s}-M_{i^{\prime} s^{\prime}}=\left(D_{s}-D_{s^{\prime}}\right) \alpha+\left(X_{i s}-X_{i^{\prime} s^{\prime}}\right) \beta+\epsilon_{i s}-\epsilon_{i^{\prime} s^{\prime}}$.

Where counties $i$ and $i$ ' are adjacent counties in states $s$ and s', which are also adjacent. Our identifying assumption in this context is that the differences in the state policy variables across these adjacent counties are uncorrelated with differences in unobservable county-level 
determinants of mobility. Given the close spatial proximity of the counties, it seems plausible that cultural factors driving mobility are likely to be very similar. However, our assumption might fail to hold if state level policy variables, such as differences in schooling expenditures, were correlated with other state differences such as the availability and effectiveness of early childhood education programs that also affected intergenerational mobility. Strong sorting across state lines on the basis of unobservable characteristics could also be problematic. We will address both of these concerns in a later section.

In all empirical specifications, we correct the standard errors for two-way clustering at the level of the state of the reference county as well as the specific state border. This allows for arbitrary independence between county pairs with one or both states in common. The standard errors are very similar if we cluster at the state border level. Our approach to inference addresses the non-independence resulting from the fact that each county can appear multiple times in our dataset as part of a county pair.

We report both estimates from unweighted regressions and regressions in which we weight the county pair by the average population in the two counties. The unweighted estimates describe the effect of a given policy on the typical border county and may take advantage of more county-level variation in policies and outcomes. The weighted estimates describe the effect of a policy on the typical resident of a border county and more efficiently average over the individual level variation at the root of the analysis. Collectively, results from both the weighted and unweighted regressions paint a similar picture.

\subsection{Educational Investment}


As previously mentioned, the primary policy variable set forth as an explanation of polity level differences in economic mobility is government investment in the human capital of children of less advantaged families. In the U.S. a primary mechanism through which the government makes such investments is the public provision of elementary and secondary education. Of course, not all school funding decisions are made at a state or local level. In particular, federal funding during this period primarily reflects Title I programs that are designed to provide compensatory funding to schools with high numbers of students from high poverty backgrounds. Hence, federal funding is likely endogenous to social factors that may determine intergenerational income mobility. This could be a problem for state and local funding as well. Additionally, institutional spending patterns may well reflect unobservable characteristics of a community that drive levels of economic mobility.

We address this issue in a couple of ways. First, since we are interested in policy variation at the sub-national level we eliminate federal funding dollars from our financial measure. We note that our results are very similar if we include federal funding dollars in this measure. Second, we take the average of the remaining per-pupil revenues (state and local) as well as the student teacher ratio across the entire state. The resulting average resource measures reflect the school finance policy of states, independent of county or district-level characteristics. For robustness, we also examine an alternative measure, county-level averages of per-pupil revenue from state and local sources as well as county-level student teacher ratios. ${ }^{6}$ Our identifying assumption in this context is that the unobservable determinants of income

\footnotetext{
${ }^{6}$ As school districts do not necessarily stay within county borders, we assign districts to the county in which the district headquarters exists. We then construct county level averages of per-pupil revenues and the student teacher ratio, weighting each school district by its enrollment of students.
} 
mobility do not differ across adjacent counties in different states. To the extent that unobservable factors vary in a manner similar to observed characteristics, we can examine the plausibility of this assumption by examining the sensitivity of our results to the inclusion of covariates.

Figure 3 illustrates average state differences in non-federal revenues. It shows that there is substantial variation in state educational resources, which do appear to follow standard geographical patterns. States in the South have, on average, lower spending than those in the northeast, for example. However, there are some exceptions. For example, Virginia has substantially higher levels of funding than West Virginia, Kentucky, and Tennessee. Similarly, Florida and Wyoming have much higher funding levels than their neighbors do.

Table 2 presents the coefficient estimates of equation (2) with the difference in per-pupil state and local revenue (in thousands of dollars) as the independent variable of interest. The standard errors are cluster-corrected at the level of the reference state and the border state. The estimates in Column 1, from a model with no covariates, suggest that there is virtually no impact of per-pupil revenues on mobility rates. However, the standard errors are sufficiently large that we cannot formally reject the possibility of moderately sized effects. For example, consider what would happen if the true effect of differences in per-pupil revenues on mobility rates was two times the standard below the point estimate (-1.10 instead of -0.26). In that case, a $\$ 1,000$ increase in per-pupil expenditures would increase mobility by 14 percent of a standard deviation in the county level distribution of income mobility (remember that a negative coefficient for this regression means that per-pupil revenues are linked to a decrease in the county level rank-rank slope, which implies an increase in income mobility rates). Examining columns 2 and 3, we see that the results are statistically insignificant if we weight the county pair by the average 
population in the two counties or include as covariates the contemporaneous cohort inequality measures for parents and children, as well as family structure. ${ }^{7}$

The remainder of the table uses the county level average measure of state and local revenue. By using county rather than state level averages, we are exploiting any discontinuous changes in education funding as we cross a state border. In this context we see a marginally statistically significant effect of state and local schooling revenues on mobility if no covariates are included. The point estimate suggests that a $\$ 1,000$ increase in revenues (just over 20 percent of the average) could reduce the correlation (multiplied by 100) between parents' and children's income ranks by 0.64 or about 8 percent of a standard deviation. This represents a moderately sized effect. This effect may not have this causal interpretation, however, instead reflecting that richer or more mobile counties may be able to generate higher funding levels. We note that either weighting observations by the average population in the county pair or including covariates causes the coefficient to attenuate substantially and become statistically insignificant. The fact that including covariates causes the results to drop is consistent with the original relationship being driven largely by county-level income characteristics.

In Table 3, we use an alternate measure of state policy differences, the student teacher ratio difference across adjacent counties. Across all specifications, we never find a statistically significant effect of the student teacher ratio on intergenerational income mobility. Furthermore, the specifications with covariates suggest an effect of the wrong sign in which increases in the student teacher ratio increase the correlation between parents' and children’s income.

\footnotetext{
${ }^{7}$ The results are similar if we use a smaller set of covariates that avoid problems of collinearity among the covariates themselves.
} 
However, the previous literature, most notably Solon (2004), explicitly suggests that it may not be the level of human capital expenditures that matters for mobility, but rather the progressivity of these expenditures. To investigate this we sort counties by the number of free lunch eligible students into quintiles within each state, and produce an average state and local revenues measure for counties in the top and bottom quintile of each state. A state's progressivity measure is then derived by dividing the revenue of the lowest free-lunch quintile by the revenue of the highest free-lunch quintile. Note that a higher value of this measure proxies a funding system that provided relatively more resources to counties with a higher proportion of poor children.

Figure 4 shows how this progressivity measure varies across states. Note that progressivity is not highly correlated with the level of funding. Utah has low funding levels but is highly progressive while Wyoming has both high funding levels and is also quite progressive. On the flip side, New York and Tennessee are examples of states with high and low funding levels, respectively, that both have relatively low levels of progressivity.

In Table 4 we follow the regression specifications from columns 1-3 of Table 2. Now, however, the difference in our progressivity measure becomes the main explanatory variable of interest. In column 1 , when no covariates or weights are present, it appears that more progressive states are more mobile in that the correlation between parents' and children's income is lower. This is statistically significant at the 10 percent level. However, when we either weight counties by population or include covariates, the coefficient flips sign and becomes statistically insignificant.

If our progressivity measure is endogenous to states with higher inequality, the inclusion of covariates that control for percentiles of the income distribution should increase the observed 
impact of progressive spending. Here, however, controlling for summary measures of the income distribution has the opposite effect. Of course, this is only one possible measure of progressivity, out of many we could construct. However, if progressive education spending were truly the primary driving force behind large geographical differences in mobility we might expect to pick up some indication through this proxy.

Collectively, then, we find little evidence to suggest that educational spending at the state and local level is a major factor in the currently observed geography of mobility. However, because adjacent states tend to have similar levels of spending, this reduces the amount of variation we have at our disposal to estimate the impact of funding. Consequently, we lack the precision to rule out the possibility that large spending changes could have moderate effects on income mobility.

Measurement error in education spending or class-sizes may lead to attenuation bias. Aggregating spending across years and counties within a state will tend to mitigate this bias. In a further effort to correct for measurement error, we formulate an IV specification where we instrument the difference in education spending and student-teacher ratio between counties based on the difference in education spending and student-teacher ratio in the non-border counties of the states in question. Our coefficient estimates from the IV specifications are similar to the previous tables. We observe no significant impact of these policies on mobility rates.

\subsection{Tax Rates}

Lefgren, McIntyre, et al. (2015), along with Holter (2015) provide models where marginal income tax rates may have a causal effect on intergenerational mobility. This is due to 
the potential impact of income tax rates on both human capital investments and occupational choice. Additionally, high tax rates may generate revenue to engage in compensatory educational investments or provide other public services with similar aims.

Both these studies also contain empirical results that suggest these tax effects may be more important to explaining national differences in mobility in developed countries than differences in educational expenditures. However, the vast differences in cultural, institutional and geographical factors between nations such as Sweden and the United States make such results highly speculative. In examining mobility differences at a finer geographical level, we may be able to more convincingly investigate this proposed mechanism of mobility differences.

Figure 5 shows that there are indeed wide differences in state level income tax rates, even between adjacent states. This is true with New York and New Jersey, Texas and Oklahoma, and Washington and Oregon. All have large differences in marginal tax rates for middle income families. The differences are similar if we examine high income families.

Table 5 shows the results of estimating equation (3) using the differences in TAXSIM generated marginal tax rates between adjacent states as the primary independent variable of interest. As in our prior analysis, we cluster correct the standard errors to take into account potential non-independence between pairs of counties along the same interstate border. In columns 1 to 3 we present the estimates from bivariate regressions of the difference in mobility rates on the difference in marginal tax rates for each of low, medium, and high income households. These rates are the marginal rate paid at $\$ 10,000$, then $\$ 50,000$, and finally $\$ 100,000$ of income respectively. The coefficients are all statistically insignificant. The confidence intervals are sufficiently wide, however, that we cannot rule out the possibility that 
tax policy could have some impact on intergenerational income mobility. But the evidence does suggest that it is not responsible for a large portion of the observed geographical variation.

In column (4), we include all three tax rates and find that the coefficients are even less precisely estimated. This is due to the fact that the marginal tax rates are highly correlated for medium and high income households (the correlation exceeds 0.9). In column (5), we weight county pairs by the average number of children in each county pair while in column (6) we include covariates. Once again, while our results do not rule out some role for tax rates, they provide no positive evidence for such a relationship. In other unreported results, we find similar estimates using average tax measures in place of marginal ones.

\subsection{Social Welfare Expenditures}

Proponents of economic models suggesting a large role for policy programs in determining economic mobility, such as the previously considered model by Solon (2004), might argue that the use of educational expenditures is a convenient shorthand for a much more comprehensive commitment to provide a safety net to the families of poor children. To the extent that this is not highly correlated with direct education funding, our results above might not capture the actual essence of such policy differences.

Thus, we use the March Current Population Survey (CPS) from 1988-1992 to create a state level index measure of aid received by the families of poor children as described in our data section. Figure 6 shows these differences graphically. As with educational expenditures we find a wide variation in the generosity of social welfare programs from state to state. 
Using these indices as the primary policy variable in equation (3) we find some evidence of a correlation between benefit generosity and intergenerational mobility in Table 6. However, these coefficients have the wrong sign to support the hypothesis that more social spending leads to less intergenerational correlation in incomes. Furthermore, the significance of this relationship is not robust to population weighting and is relatively small in magnitude, with a doubling of real per-capital assistance required to change mobility by one-third of a standard deviation, and in the opposite direction of the common hypothesis.

To this point, we find little positive evidence for the primacy of the most commonly suggested state-level policy mechanisms in explaining observed differences in income mobility. ${ }^{8}$ However, these results may well be attenuated due to omission of relevant state level factors. We will address this possibility in the next section.

\section{An Omnibus test of the importance of state policies}

The tests in section 4 possess the advantage of narrowly targeting specific policies that we have theoretical reasons to believe should matter a lot for mobility. However, there is some concern that they may fail to capture important state policy differences that affect mobility and may thus present a biased picture of policy effects. Furthermore, our policy variables could be subject to measurement error, which could also attenuate the estimates. This error may arise through issues in aggregating the data spatially or over a timeframe that corresponds imperfectly to the exposure of children to state policies, as well as the more standard mismeasurement of

\footnotetext{
${ }^{8}$ When one includes all policy variables including school finance, marginal tax rates, and social welfare expenditures we see a similar picture. In particular, once one controls for covariates only social spending significantly correlates with mobility, albeit with a perverse sign.
} 
data. While we have already presented multiple attempts to account for measurement error, in this section we will address these potential measurement problems more generally, by adopting an alternative empirical framework.

We use the county level differences in mobility, together with the conceptual framework sometimes (imprecisely) referred to as a geographical discontinuity design to develop an omnibus test for the income mobility effects of state-level policy differences in their totality. This will formalize the visual intuition provided by figures (1) and (2) about the relationship between state boundaries and mobility changes.

\subsection{Model}

We begin by specifying a statistical model of mobility, similar to equation (1).

(3) $M_{\text {is }}=X_{i s} \beta+\theta_{s}+\epsilon_{i s}$.

As before, mobility in a particular state-county-observation depends on county specific demographic factors and state-specific characteristics. Now, however, these state characteristics include all relevant policy distinctions.

First, consider the difference in mobility between adjacent counties in adjacent states, which is given by:

(4) $M_{i s}-M_{i^{\prime} s}=\left(X_{i s}-X_{i^{\prime} s}\right) \beta+\epsilon_{i s}-\epsilon_{i^{\prime} s}$.

Now, however, we focus on the variance of the unobservable component of this difference:

(5) $\operatorname{var}\left(\epsilon_{i s}-\epsilon_{i^{\prime} s}\right)=2 \sigma_{\epsilon}^{2}-2 \operatorname{cov}\left(\epsilon_{i s}, \epsilon_{i^{\prime} s}\right)$. 
Equation (5) suggests an important statistical detail, namely if the unobservable determinants of mobility between adjacent counties within the same state are highly correlated, the variance of this unobservable difference may be quite small.

Now consider the difference in mobility between adjacent counties in adjacent states, which is given by:

(6) $M_{i s}-M_{i^{\prime} s^{\prime}}=\left(X_{i s}-X_{i^{\prime} s^{\prime}}\right) \beta+\theta_{s}-\theta_{s^{\prime}}+\epsilon_{i s}-\epsilon_{i^{\prime} s^{\prime}}$

As is standard, we assume $\theta_{s}$ is uncorrelated with $\epsilon_{i s}$. The variance in the difference of unobservable determinants of mobility in this context is given by:

(7) $\operatorname{var}\left(\theta_{s}-\theta_{s^{\prime}}+\epsilon_{i s}-\epsilon_{i^{\prime} s^{\prime}}\right)=2 \sigma_{\epsilon}^{2}-2 \operatorname{cov}\left(\epsilon_{i s}, \epsilon_{i^{\prime} s}\right)+2 \sigma_{\theta}^{2}-2 \operatorname{cov}\left(\theta_{s}, \theta_{s^{\prime}}\right)$

This statistical model suggests a general identification strategy for examining the variance in state-level determinants of intergenerational mobility. In particular, we regress the between county difference in intergenerational mobility on the corresponding differences in covariates as in equations (4) and (6). We then calculate the residual for each pair-wise difference between counties $i$ and $i^{\prime}$, which we designate $\hat{e}_{i i^{\prime}}$. We then square this residual and perform the following second stage regression:

(8) $\hat{e}_{i i^{\prime}}^{2}=\gamma_{0}+\gamma_{1}$ different state $e_{i i^{\prime}}+\eta_{i i^{\prime}}$.

In this model, the estimate of $\gamma_{0}$ converges to the variance of the differences between unobservable determinants of mobility across adjacent counties within the same state, $2 \sigma_{\epsilon}^{2}-$ $2 \operatorname{cov}\left(\epsilon_{i s}, \epsilon_{i^{\prime} s}\right)$. Similarly, the estimate of $\gamma_{1}$ converges to the variance of the differences between unobservable determinants of mobility across adjacent states, $2 \sigma_{\theta}^{2}-2 \operatorname{cov}\left(\theta_{s}, \theta_{s^{\prime}}\right)$. A failure to reject the null hypothesis that $\gamma_{1}=0$ suggests that the unobservable determinants of 
mobility are no different across county lines that cross state borders than across county lines within a state. This could be because $\sigma_{\theta}^{2}$ is small, meaning there is little variation generally across state policies that would translate into differences in intergenerational mobility.

Alternatively, $\operatorname{cov}\left(\theta_{s}, \theta_{s^{\prime}}\right)$ could be positive and large if adjacent states tended to have more policy similarities than all states as a group. On the other hand, if we reject the null hypothesis to find that $\gamma_{1}>0$, we can conclude that mobility varies more across state lines than county lines within a state. As long as adjacent states were more similar than states in general, this procedure would provide a lower bound for the importance of state policies in determining intergenerational mobility.

\subsection{Omnibus Tests in the Entire Sample}

Table 7 reports the results of this exercise. Column (1) contains results from a model with no covariates. Recall that we have multiplied our intergenerational income correlations by 100. The constant can be interpreted as an estimate of the variance in the difference in mobility rates across adjacent counties within the same state. Taking the square root of this coefficient estimate 47.89, produces an implied standard deviation of the difference in mobility rates across adjacent counties within the same state of 6.92. In this same regression, the coefficient on the different state dummy variable can be interpreted as an estimate of how much greater the variance in mobility rates is when considering adjacent counties in different states.

If this term were large and positive, it would indicate there is more variation in mobility outcomes when we cross a state border than an intra-state county border. This could be interpreted as evidence for the effect of state policies on county-level mobility. However, the 
estimated coefficient is 2.13 and is statistically insignificant from zero. Even treating the coefficient estimate as the truth would mean that the standard deviation of the difference in mobility rates across adjacent counties that also cross state lines is 7.07 , which is almost the same as that for intra-state borders. Even accepting the largest value in the 95 percent confidence interval would translate to a standard deviation of the difference in mobility rates across states no larger than 7.56, again quite close to the difference in mobility rates across counties within a state. Weighting the regression by the average number of children in a county pair, shown in column 2, makes little difference.

While there is little evidence here that observable characteristics differ more across state borders than county borders, it may nevertheless be useful to examine how our primary results differ when we control for observable characteristics. To do so we first estimate equation (6) in which we regress the difference in mobility rates across adjacent counties on a vector of differences in observed characteristics.

Table 8 presents the estimates from this preliminary regression. It shows that teen birth rates are highly predictive for income immobility. In particular, a ten percentage point increase in the fraction of children born to teen mothers increases the rank-rank slope (multiplied by 100) between parents' and children’s incomes by 4.38, which represents more than half a standard deviation in the distribution of mobility rates across counties. This suggests that in counties with high levels of teen pregnancy, mobility rates are much lower than in counties with few teen births. Further investigation of the table shows that mobility rates are significantly higher (the 
intergenerational correlation in income lower) in counties with more middle class ${ }^{9}$ families and in counties with more egalitarian incomes for the child's cohort.

We then take the residuals from this regression, square them, and then use them as the dependent variable when we estimate equation (8). This provides us with the estimates found in column 3 of Table 7 . Recalling that the estimate of the constant term measures the variance in the unobservable determinants of mobility across adjacent counties, we see that the addition of covariates has the expected effect of reducing the variance due to unobserved factors to 34.79 , implying a standard deviation 5.89. However, the coefficient on different state remains small and statistically insignificant. Taken at face value it denotes an increase in variance associated with moving across state lines only 0.35 greater than across county lines (implying a standard deviation of the difference in mobility rates of adjacent counties in different states of 6.18).

\subsection{Looking Where the Differences Are Greatest}

This initial evidence suggests that differences in state policy menus have, on average, little impact on current income mobility differences of adjacent states. However, this may be because most adjacent states have similar policy bundles. This could lead to a situation in which average differences in mobility across state lines appear small, but some relevant areas exist in which the differences are actually large. Finding no effect of policy differences on mobility across the average state border, we turn to a sample of pairs of neighboring states that have the starkest overall differences in intergenerational mobility levels and look for discontinuous changes in mobility across those state borders.

\footnotetext{
${ }^{9}$ See Section 3, page 8 for our definition of middle class
} 
To illustrate this process, consider an example involving the adjacent states of Texas and Louisiana, which have a large difference in average income mobility. In Texas the rank order correlation multiplied by 100 between parents and children's income is 31.9, in Louisiana it is 39.4. Some of this difference may be due to state policies in Texas that increase economic opportunity relative to Louisiana. It is also possible, however, that the differences are not driven by state policies but merely correspond to differences in culture, geography or economic conditions that change smoothly within and across states.

Figure 7 shows a county map of the Texas-Louisiana border region. It shows that Panola County, Texas and DeSoto Parish, Louisiana share a common border. On the other hand, Rusk County, Texas is adjacent to Panola County but does not border Louisiana. Similarly, Red River Parish, Louisiana is adjacent to DeSoto Parish but not to Texas. Our methodology suggests that if the differences in mobility between states are not attributable to state policies, the differences in mobility across the state border should be similar to the differences across the adjacent counties within both Texas and Louisiana. If, on the other hand, the differences are caused by state policies, we should expect a larger difference in mobility between Panola County and D eSoto Parish than between either the Panola - Rusk or DeSoto - Red River pairs.

In this example, the mobility differences are 2.3 for Panola - Rusk and 12.0 for DeSoto Red River but only 1.9 for the DeSoto - Panola difference. Since the difference across the state border is less than the difference from moving across county borders within either state, this example would provide no evidence that policy differences between Texas and Louisiana are important determinants of income mobility differences.

Generalizing from this example, we focus our analysis on comparisons between all adjacent states that have differences in the mobility rate that exceed one standard deviation in the 
overall distribution of state mobility rates. We exclude the District of Columbia and Delaware from this analysis since they lack non-border counties. Our analysis includes 12 comparisons between states with very different mobility rates. ${ }^{10}$ Figure 8 illustrates the relevant states and borders as well as the counties included in the analysis sample. Within this sample, the average rank-order correlation multiplied by 100 between parents' and children's income is 30 in the more mobile states and 36 in the less mobile states.

Because this approach focuses on comparisons between states with different levels of mobility, mobility measures will tend to increase as we move away from the center of the less mobile state towards the center of the more mobile state, regardless of whether state polices have any impact or not. To address this concern, we implement a strategy inspired by the regression discontinuity design (RD) commonly used in empirical microeconomic research. In this analysis, our unit of observation is the county.

We limit our sample to those counties on the border between the two states under examination as well as the counties that lie adjacent to the border counties but that are not on the border themselves, which we call second-tier counties. We define the indicator variable "Mobile State” as being in the higher mobility state and allow the degree of mobility to vary linearly across counties near the state line. This means we assign an index variable that takes on a value of 0 for border counties in the high mobility state while second-tier counties in that state are assigned an index value of 1 . Border counties in the low mobility state receive an index value of -1 while second-tier counties in that same state are assigned an index value of -2. Intuitively, the

\footnotetext{
10 The twelve comparisons include Arkansas and Mississippi, Florida and Alabama, Iowa and Illinois, Michigan and Ohio, Texas and Louisiana, California and Arizona, Colorado and Kansas, Colorado and Oklahoma, Colorado and Nebraska, Texas and Arkansas, Virginia and North Carolina, and Wyoming and Nebraska.
} 
index represents a county's distance from the state border in question. More formally, our specification is:

(9) $\quad M_{i s}=\beta_{0}+\beta_{1}$ Mobile State $_{s}+\beta_{2}$ index $_{i s}+\beta_{3} X_{i s}+\epsilon_{i s}$

If the differences in mobility between these states is driven by differences in polices, we expect $\beta_{1}$ to be positive and statistically significant. However, if the differences in mobility are driven by spatially correlated cultural or demographic factors, we would expect $\beta_{2}$ to be statistically significant but $\beta_{1}$ to be statistically insignificant.

We report the results of this analysis in Table 9. All standard errors are cluster-corrected at the state level. ${ }^{11}$ All specifications include fixed effects for each pair of states under consideration (for example a single fixed effect for all counties in Texas and Louisiana). For column 1 , we modify equation (9), by omitting both the index variable and all state level covariates other than the comparison fixed effects. By construction, the mobile state indicator in this context measures the average difference in mobility between the border and second tier counties associated with being in the more mobile state of each selected pairing, which in this case is -1.47 . Column 4 alters the regression by weighting using the number of children used to compute the mobility measure in each county. The coefficient rises in absolute value to -3.91. It is notable, however, that both of these estimates are smaller than the average difference in mobility between the mobile and immobile states, suggesting that counties along the borders are more similar than their states as a whole.

\footnotetext{
${ }^{11}$ We only leverage information from 19 separate states, which may be small relative to what is preferred when using cluster-corrected standard errors. However, in this case our inference is similar to what we find using White standard errors that only correct for potential heteroskedasticity.
} 
With this as a baseline, we next implement our RD inspired approach by inserting the geographical index variable. In columns 2 and 5, we present the results for the unweighted and weighted cases, respectively. In both cases the addition of the index variable sees the state indicator coefficient attenuate in magnitude by roughly two-thirds. Additionally, in this setting we are unable to reject the null hypothesis that there are, in fact, no mobility differences due to crossing a state boundary.

This pattern of results is consistent with a hypothesis that the differences in state average mobility rates are driven by spatially correlated factors that do not respect state boundaries. The addition of the measures of family structure and income previously used as covariates (see Table 8) in columns 3 and 6 only strengthens this conclusion, as the high mobility coefficient further attenuates. Or put more simply, even the states which have the largest average differences in mobility appear to differ in characteristics that change smoothly across state borders. If we were to interpret these estimates, conditional on covariates, as causal, the coefficients of columns 3 and 6 as given would suggest that only a small portion of average mobility differences, at most 2.5\%-11.5\%, could be explained by state-level policy differences, even when looking in the starkest state contrasts. Of course, this interpretation assumes there are no discontinuous changes across borders in unmeasured covariates, or selective sorting across borders in ways that matter for mobility. We address these potential threats to identification in the next section.

\section{Program evaluations and county level evidence: why do they diverge?}

The results of the two previous sections seem puzzling in light of the numerous program evaluations that find positive effects of specific interventions on the educational and labor 
market outcomes of disadvantaged children. If we know that experimentally validated policies can dramatically improve the outcomes of poor children, how can it be that there is so little evidence, at the county level, that state policy differences explain more than a small fraction of actual mobility differences?

In this section, we consider a few possibilities, which can be grouped under two headings: potential flaws in the county level-estimation, and potential differences between published experiments or quasi-experiments, and state level-policies. It is important to note that we do not expect that there is only one correct answer to this question; a number of factors may combine to produce the divergence. A definitive answer is beyond the scope of this paper. Nevertheless, we will attempt to confront potential problems with the estimates we have presented in this paper, as well as provide a discussion of the possible differences between the program evaluations and implemented state policies.

\subsection{Threats to Identification}

The primary threats to the validity of our results come from the possibility of boundary manipulation and from population mobility (a specific form of measurement error). In the first case, the discontinuity design assumes that people do not sort themselves across the discontinuity (state border) in response to the policy differences. In the second case, even random migration can lead to an attenuation of observable policy effects since a person born in a particular state is not exposed to that state's policies for their entire life. Instead, they are exposed to that state's policies until they move, at which point they are exposed to a different policy menu. While our 
omnibus test focuses on correcting for measurement error in types or extent of policies, it would not correct for this mobility effect.

\subsubsection{Non-random sorting across state borders}

First, let us consider the assumption that there is no sorting of people across state lines based on unobservable characteristics in a manner that would mask the effects of state mobilityenhancing policies. This is not as tenuous an assumption as it might seem at first glance. To reverse our results it would require the type of sorting in which families with inherently less propensity to experience income mobility, disproportionately locate in states with mobility enhancing policies. If this sort of perverse matching existed, it seems almost certain that it would also be reflected in differences across observable characteristics. However, our results tend to be quite robust to the inclusion of observable characteristics.

Furthermore, we can directly examine whether differences in our policy measures correlate with differences in observable characteristics. ${ }^{12}$ To aggregate our observed covariates into a single index of mobility, we regress county-level income mobility rates on the sixteen observed covariates listed in Table 1 . Then, the predicted mobility rate from this regression becomes a summary measure of all the covariates.

For Table 10, we re-estimate a model similar to equation (2), but using an observed characteristic or our index of observed characteristics as the dependent variable instead of economic mobility. Our estimates are unweighted and include no covariates on the right hand

\footnotetext{
12 These covariates include the fraction of children born to teen parents, fraction of middle class families, as well as
} income statistics for families in both the parents and children's cohorts. 
side. The table reports p-values for tests in which the null hypothesis is that differences in state policies are unrelated to differences in the specified observable characteristic.

Focusing first on the index of mobility that combines all observed population characteristics, we find that differences in per-pupil funding, marginal tax rates, and social welfare expenditures are all uncorrelated with this index. However, areas with larger studentteacher ratios have characteristics predicting slightly higher levels of mobility, though this is significant at only the 10 percent level. If unobservable characteristics have the same relationship with this policy as observable factors, the impact of student-teacher ratio on intergenerational mobility is likely to be somewhat understated. We see evidence of the magnitude of this impact when observed characteristics are included in Table 3. However, we also find that the results are insensitive to the use of covariates once we weight counties by population.

On the other hand, border counties in states with more progressive educational funding structures have observables that predict more income mobility. This would suggest that any observed impact of progressivity might be overstated. Table 4 shows that controlling for observed characteristics does eliminate the observed impact of progressivity. Once again, weighting the results by population reduces the sensitivity of the estimates to the inclusion of covariates. Marginal tax rates are not correlated with the index of mobility.

If we look in more detail to see what type of sorting occurs on the basis of observed characteristics, we notice that states that spend more on education have higher income households. However, this does little to explain mobility rates. Student teacher ratio and progressivity of education funding are significantly correlated to the index of mobility but tend not to be strongly correlated with many elements of the index itself. Households with higher 
incomes sort to states with lower marginal tax rates, though this does little to predict income mobility rates. Collectively, though sorting does occur on the basis of policy variables, it does not appear that such sorting, at least on the basis of observed characteristics, can explain more than a little of the divergence between our results and our expectations based on the program evaluation literature.

Moving on to our first omnibus test of the impact of state policies, we assume that the unobservable characteristics vary no more across state lines than they do across county lines. While this is not empirically testable, we can test whether observed county characteristics differ more between adjacent counties in different states than between other adjacent counties. We do so in a manner analogous to our analyses from Section 5 . We compute the difference in the observed county characteristics shown in Table 1 across adjacent counties and square it. We then regress this squared difference on a constant and a dummy variable indicating whether the adjacent county is in a different state.

Table 11, Column 1 provides p-values for the standard hypothesis test on each of those factors. We find that of sixteen different observed characteristics, only one, the income share of the top $1 \%$, varies more significantly across state borders than across county borders at the 5 percent level. Our index of observed characteristics does appear to vary slightly more across state lines than county lines. This is significant at only the 10 percent level. Combining these results with the fact that the Table 2 estimates are similar with and without covariates suggests that those Table 2 findings are unlikely to be meaningfully influenced by the non-random sorting of households across state borders.

In the second column of Table 11, we estimate equation (9), replacing the mobility rate with the covariate in question. We test to see if there exist discrete changes in observable 
characteristics between adjacent states for which mobility differences are the greatest. The table reports the p-values testing the null that the specific observed characteristic does not significantly change at the border between the mobile and less mobile state. We find that none of the observed characteristics are significantly different as one moves from the less mobile to the more mobile state. Furthermore, the index of mobility does not change significantly as one crosses from an immobile to a mobile state.

\subsubsection{Migration}

To obtain a rough approximation of how much migration might matter for attenuation through reduced policy exposure; we examine the distribution of birth-state residence for individuals in the 2000 Census Public Use Microsamples (Ruggles, Alexander, et al. 2010). In Figure 9, we examine the fraction of individuals at each age that currently live in the state in which they were born. This allows us to approximate the extent to which the analysis cohort was exposed to the policies of their birth state in childhood. We see that at age 17, eighty percent of

youth are still living in the state in which they were born. This suggests that our strategy is likely to be effective at identifying the impacts of state policies that affect primarily young people, such as those regarding school and taxation of parents' incomes. However, the figure also suggests that the effectiveness of this identification strategy is clearly decreasing in the age at which the policy is expected to impact the cohort, so that, for example, estimates for labor market policies that increase mobility by improving the outcomes of adults in their thirties are likely to be more attenuated. 
We can further quantify the likely extent of the attenuation via simulation. For simplicity, we assume that the policy effect of a location on mobility is linear over time. Thus, a household's mobility effect is the average of the time weighted mobility effects of the states they have lived in. This assumption is consistent with the work of Chetty and Hendren (2018a, 2018b). As a borderline case we consider children in families who spent half their childhood in the reference state and half in a random state. This case will tend to overstate the degree of bias.

Using these assumptions, we perform simulations with 25 high mobility states and 25 low mobility states, each with 20,000 parent-child households. We assume that the rank-rank slope is 0.1 in high mobility states and 0.3 in low mobility states. Using an empirically derived figure of 20 percent cross-state mobility among youth, the measured mobility differences between mobile and immobile states attenuates by about 10 percent (from 0.2 to 0.179 ). If we doubled the fraction of mobile youth, to 40 percent, the difference in mobility across locations is attenuated by 20 percent. This attenuation will be smaller if people tend to migrate to places with similar levels of intergenerational income mobility. This suggests that while our estimates of effects of state policies may be understated due to migration, this bias is unlikely to be very large in magnitude-particularly for policies aimed at young children. ${ }^{13}$

It is also helpful to examine directly the extent to which individuals in border counties migrate to other states and whether this migration appears non-random. To do so we collected IRS SOI migration data for 2004-2005, as described in our data section. Using this migration

\footnotetext{
${ }^{13}$ We also performed simulations to examine the impact of non-random migration. Under the assumptions described earlier, if who migrates within a state is random but people are more likely to migrate from low mobility places than high mobility places, the bias is unchanged relative to the case in which moves are equally likely in both mobile and immobile places. If families who are latently more mobile themselves are likely to migrate to places with higher mobility and vice versa, this will tend to further reduce the observed policy effects on mobility. The magnitude tends to be quite small, however, unless the differences in mobility for movers from mobile and nonmobile places is quite large.
} 
data, we calculate the total migrant inflows and outflows for each of the 125 counties in our border-county analysis sample. ${ }^{14}$ These inflows of migrants could have originated from anywhere in the U.S. or even from other countries, whereas the outflows, by definition, must have come from that particular county. We then calculate the total inflow of migrants for each county that originated in one of our defined "border counties" in the same state. Next we calculate the total migrant inflows into each county from one of the "border counties" in the adjacent state. If these migrant inflows are large, we would be particularly concerned that there was systematic migration across borders, potentially as a result of policies or characteristics which influence income mobility. We transform each of our total migrant inflow and outflow variables into percentages of the non-migrant taxpayer population of any given county by dividing the inflows or outflows of tax exemptions by the total tax exemptions in a county.

Table 12 provides summary statistics for these inflow and outflow variables in level and percentage terms. These measurements show that the average county in our analysis sample had between 4 and 5 thousand total migrants (coming and leaving) between 2004 and 2005. Considering inflows, on average about 705 migrants came from border counties in the same state whereas only about 170 came from border counties in the adjacent state. In percentage terms, roughly 6.7 percent of the population in the average county appears to have moved in or out, but less than 1 percent came from border counties in the same state and less than 0.4 percent come from the border counties in the adjacent state. While a fair percentage of households migrate into and out of a county each year, most migration is not occurring between adjacent counties. Even less is occurring between adjacent counties in different states, which would be the case if

\footnotetext{
${ }^{14}$ This uses the number of "exemptions" on filed returns that changed addresses during the 2004-2005 years. These numbers are more likely to capture the number of people that move rather than simple household numbers.
} 
households were making small moves on the basis of state-level policies that drive income mobility.

We further separate the border counties into those from low- versus high-mobility states and examine whether there were differences in migration rates between the two groups. These results can be seen in the final two rows of Table 12. The data suggests that the 56 counties in high income-mobility states have about 0.25 percent of their population coming from the border counties of adjacent states compared to 0.46 percent for the counties in low income-mobility states. These differences are neither quantitatively nor statistically significant (their 95\% confidence intervals overlap in the Table).

\subsubsection{Other issues}

While we view manipulation and measurement error as the key potential sources of bias in these estimates, there are a couple of other possibilities. The first possibility is that the important state level policies aimed to increase mobility might create spillover benefits in adjacent states. Such spillovers might help explain why there are few observed mobility differences across state borders. In some cases, the aggregation of individual level variables could also lead to bias. Unfortunately, the data to address these concerns are unavailable to us but could be a direction for future research.

\subsection{Program evaluations and public policy}


While it is possible that the apparent disagreement between the program evaluation literature and our present results is due to empirical issues in our study, we should also consider the possibility that some of the difference is due to discrepancies between the programs as evaluated and the actual, full public policy implementations of those programs. Indeed, this is not the first study that fails to find the predicted cross-sectional effects of some mobility-targeted policies. For example, Rothstein (2019) finds little evidence that differences in school policy play a major role in creating geographical differences in mobility. Kearney and Levine (2015) find little relationship between state policies and teen pregnancy rates. This evidence is also consistent with the recent work of Chetty and Hendren (2018a), which implies that the primary determinants of mobility work at a much smaller geographical level, such as the neighborhood.

Many quasi-experimental program evaluations fail to convey the obstacles of politics, scale, and persistence that differentiate state-level policies from most common program evaluation environments. First, there are potential political and logistical obstacles to implementing state policies in a manner that materially reduces intergenerational income mobility. In addition to being potentially effective at raising incomes for poorer children, policies would need to be provided to large numbers of a state's children, yet differentially targeted to children from low-income families. If either of these two conditions fail to hold, potentially effective policies in a controlled econometric study may not generate measureable variation in intergenerational income mobility across states.

For example, Dobbie and Fryer (2011) demonstrate that high quality charter and community programs such as the Harlem Chidren's Zone (HCZ) can eliminate the achievement gap between black and white students in mathematics. While this is very likely to increase the eventual earnings of those who enroll in such schools, currently only a very small fraction of 
students within any state enroll. Additionally, such programs are extremely expensive. A student in HCZ are in school for approximately twice as many hours as regular students making it politically challenging to provide such programs to more than a miniscule fraction of low income children who might benefit.

Beyond the simple factor of cost, other logistical issues or unintended consequences can prevent small-scale programs from affecting economic mobility on a statewide scale. For example, Chetty et al. (2011) find that smaller classes raised the achievement of poor children in an experimental setting. However, statewide programs for class-size reduction in California faced problems of providing sufficient qualified teachers and classrooms when implementing such an expansion, with a result that many poorer school districts may have had students made worse off by the policy (Jepsen \& Rivkin 2009).

In some cases, expensive polices such as increases in educational spending and class-size reductions have been implemented at a large scale. However, even if those programs avoid unintended consequences, they are not necessarily targeted disproportionately to children from low income families. For example, examining a sample of men that predates our own analysis, Card and Krueger (1992) find that state-level increases in educational spending raise the return to education. To the extent, however, that children from high income families get more education than children from low income families, this may reduce relative income mobility instead of increasing it. More broadly, unless government programs are targeted towards, or are more effective for, low-income children than for high-income children, their effect on relative economic mobility will be muted. Given the political influence of middle- and high-income families, it is unsurprising that in many cases the delivery of educational and other resources does not occur in a manner to maximize intergenerational economic mobility. Studies of recent 
increases in school funding in response to adequacy lawsuits, for example, show that states respond to such verdicts by increasing funding for both the highest and lowest poverty school districts (Sims 2011). Alternatively, higher income parents may just be better at securing more resources from schools outside the political process in ways that offset the policy-induced resource allocation.

Finally, even if successfully implemented, the effect sizes of these policies on earnings must be large enough to observe measurable differences in adult income. Many policies that are effective at increasing educational attainment and achievement do not have statistically significant effect on earnings. This is the case in both Chetty et al. (2011) and Garces, Thomas, and Currie (2002). Thus while these programs could well increase earnings, the effect is not measurable in their samples because of the enormous variability in earnings not attributable to the treatment itself. It is perhaps unsurprising then, that similar programs implemented at the state level would not be able to produce changes in child income large enough to generate measurable differences in intergenerational income mobility. Consequently, it is not always straightforward to implement even potentially effective policy levers in a way that overcomes the enormous advantage of being born into an upper-middle class family.

\section{Conclusion}

There is substantial geographic variation in the intergenerational income mobility rates found in the United States. Indeed, Chetty, Hendren, et al. (2014a) note that some counties in the U.S. have mobility rates comparable to the most mobile societies in Scandinavia, while children born in different regions face mobility prospects lower than any recorded in a developed nation. 
Understanding why these geographical differences occur is an important element in both an academic exploration of intergenerational income correlation and any policy discussion of responses to economic inequality. Furthermore, examining geographical variation within a single country complements existing cross-country research on the causes of inequality.

The original goal of this study was to try to find out which type of state-level policy choices were most important in explaining these geographical differences. There were many candidates, such as education spending levels or progressivity, other types of social welfare spending, or differences it tax rates. Most of these were derived either from commonly used models or from successful empirical program evaluations. What we found, instead, was that there is very little county-level evidence that states, as policy-making entities, do much to explain the contemporary geographical patterns of economic mobility in the United States.

Because of our concerns about the difficulty of identifying and measuring the relevant state level policies, we further developed an omnibus test to look for differential effects of the entire states-level policy portfolio. In this, we drew inspiration from common empirical microeconomic methods of identification. The results from this test also suggest that current state policy variation plays little role in explaining mobility patterns. While mobility creates potential challenges to our identification, we present evidence that sorting and migration patterns are unlikely to account for our failure to find large policy effects for policies targeted at children. These findings lend support to the general invariance of most of our results to the inclusion of covariates. We present evidence that households with certain demographic patterns predicting income mobility do not change discontinuously at state borders. Taken as a whole, the county level evidence suggests that state policy differences play at most a small role in explaining geographical differences in mobility. 
These analyses, like all identification strategies, come with unavoidable limitations. However, our findings provide credible evidence that the variability in state policies in our data explains little of the cross-sectional variation in intergenerational mobility. This stands in contrast to the voluminous program evaluation literature, which shows that some policies are indeed effective for improving the economic outcomes of the disadvantaged. Further research on understanding why these results diverge is essential to making responsible policy choices aimed at increasing economic mobility. Indeed, we view these results as a call to further investigation on which current or potential policies might hold the most promise to increase income mobility in the United States. 


\section{References}

Balafoutas, L., Kocher, M. G., Putterman, L., \& Sutter, M. (2013). Equality, equity and incentives: An experiment. European Economic Review, 32-51.

Bayer, P., \& Charles, K. K. (2016). Divergent Paths: Structural Change, Economic Rank, and the Evolution of Black-White Earnings Differences, 1940-2014 (No. w22797). National Bureau of Economic Research.

Becker, G. S., \& Tomes, N. (1979). An equilibrium theory of the distribution of income and intergenerational mobility. The Journal of Political Economy, 1153-1189.

Blanden, J. (2009). How much can we learn from international comparisons of intergenerational mobility? Center for Economics of Education Discussion Paper 111.

Card, D., Domnisoru, C., \& Taylor, L. (2018). The intergenerational transmission of human capital: Evidence from the golden age of upward mobility. NBER Working Paper 25000.

Card, D., \& Krueger, A. B. (1992). School quality and black-white relative earnings: A direct assessment. The Quarterly Journal of Economics, 107(1), 151-200.

Chetty, R., \& Hendren, N. (2018a). The impacts of neighborhoods on intergenerational mobility I: Childhood exposure effects. The Quarterly Journal of Economics, 133(3), 1107-1162.

Chetty, R., \& Hendren, N. (2018b). The impacts of neighborhoods on intergenerational mobility II: County-level estimates. The Quarterly Journal of Economics, 133(3), 1163-1228.

Chetty, R., \& Hendren, N. (2015). The Impacts of Neighborhoods on Intergenerational Mobility: Childhood Exposure Effects and County-Level Estimates. Working Paper. Retrieved from http://www.equality-of-opportunity. org/images/nbhds paper. pdf (accessed May 5, 2015).

Chetty, R., Hendren, N., \& Katz, L. F. (2016). The Effects of Exposure to Better Neighborhoods on Children: New Evidence from the Moving to Opportunity Experiment. American Economic Review 106, 855-902

Chetty, R., Hendren, N., Kline, P., \& Saez, E. (2014a). Where is the land of Opportunity? The Geography of Intergenerational Mobility in the United States. The Quarterly Journal of Economics. doi:10.1093/qje/qju022

Chetty, R., Hendren, N., Kline, P., Saez, E., \& Turner, N. (2014b). Equality of Opportunity Project Database: Geography of Intergenerational Mobility. Retrieved from http://www.equality-of-opportunity.org/index.php/data.

Chetty, R., Hendren, N., Kline, P., Saez, E., \& Turner, N. (2014c). Is the United States Still a Land of Opportunity? Recent Trends in Intergenerational Mobility. American Economic Review, 104(5), 141-147. doi:doi: 10.1257/aer.104.5.141

Chetty, R., Friedman, J. N., Hilger, N., Saez, E., Schanzenbach, D. W., \& Yagan, D. (2011). How does your kindergarten classroom affect your earnings? Evidence from Project STAR. The Quarterly Journal of Economics 126(4), 1593-1660.

Corak, M. (2006). Do poor children become poor adults? Lessons from a cross-country comparison of generational earnings mobility. Research on Economic Inequality, 13, 143-188.

Dahl, G. B., \& Lochner, L. (2012). The impact of family income on child achievement: Evidence from the earned income tax credit. American Economic Review, 102(5), 1927-56.

Dube, A., Lester, T. W., \& Reich, M. (2010). Minimum wage effects across state borders: Estimates using contiguous counties. The Review of Economics and Statistics, 92(4), 945964. 
Feenberg, D., \& Coutts, E. (1993). An introduction to the TAXSIM model. Journal of Policy Analysis and Management, 12(1), 189-194.

Garces, E., Thomas, D., \& Currie, J. (2002). Longer-Term Effects of Head Start. American Economic Review, 92(4), 999-1012.

Grawe, N. D. (2010). Primary and Secondary School Quality and Intergenerational Earnings Mobility. Journal of Human Capital, 4(4), 331-364.

Gross, E. (2005). Internal revenue service area-to-area migration data: Strengths, limitations, and current trends. Paper presented at the Proceedings of the Section on Government Statistics.

Hanushek, E. A. (1986). The Economics of Schooling: Production and Efficiency in Public Schools. Journal of Economic Literature, 24(3), 1141-1177.

Hedges, L. V., Laine, R. D., \& Greenwald, R. (1994). An exchange: Part I: Does money matter? A meta-analysis of studies of the effects of differential school inputs on student outcomes. Educational researcher, 23(3), 5-14.

Holmes, T. J. (1998). The effect of state policies on the location of manufacturing: Evidence from state borders. Journal of Political Economy, 106(4), 667-705.

Holter, H. A. (2015). Accounting for cross country differences in intergenerational earnings persistence: the impact of taxation and public education expenditure. Quantitative Economics, 6(2), 385-428.

Ichino, A., Karabarbounis, L., \& Moretti, E. (2011). The Political Economy of Intergenerational Income Mobility. Economic Inquiry, 49(1), 47-69. doi:http://www.blackwellsynergy.com/loi/ecin/

Jäntti, M., Bratsberg, B., Røed, K., Raaum, O., Naylor, R., Österbacka, E., . . Eriksson, T. (2006). American Exceptionalism in a New Light: A Comparison of Intergenerational Earnings Mobility in the Nordic Countries, the United Kingdom and the United States. IZA Discussion Paper 1938. IZA. Bonn, Germany.

Jepsen, C., \& Rivkin, S. (2009). Class size reduction and student achievement the potential tradeoff between teacher quality and class size. Journal of human resources, 44(1), 223250.

Kearney, M. S., \& Levine, P. B. (2015). Investigating recent trends in the US teen birth rate. Journal of Health Economics 41, 15-29.

Lefgren, L. J., McIntyre, F., \& Sims, D. P. (2015). Beyond education and fairness: A labor market taxation model for the Great Gatsby Curve. Economic Inquiry, 53(2), 962-978.

Mayer, S. E., \& Lopoo, L. M. (2008). Government spending and intergenerational mobility. Journal of Public Economics, 92(1), 139-158.

Mazumder, B. (2015). Estimating the Intergenerational Elasticity and Rank Association in the U.S.: Overcoming the Current Limitations of Tax Data. Federal Reserve Bank of Chicago, working paper No. 2015-04.

Oxoby, R. J., \& Spraggon, J. (2008). Mine and yours: Property rights in dictator games. Journal of Economic Behavior \& Organization, 65(3), 703-713.

Pekkarinen, T., Uusitalo, R., \& Kerr, S. (2009). School Tracking and Intergenerational Income Mobility: Evidence from the Finnish Comprehensive School Reform. Journal of Public Economics, 93(7-8), 965-973. doi:http://www.elsevier.com/locate/inca/505578/

Pew Charitable Trusts Economic Mobility Project. 2012. "Pursuing the American Dream: Economic Mobility across Generations.” Survey. 
Pew Charitable Trusts Economic Mobility Project. 2011. "Economic Mobility and the American Dream." Survey.

Rothstein, J. (2019). Inequality of educational opportunity? Schools as mediators of the intergenerational transmission of income. Journal of Labor Economics 37, S85-S123.

Ruggles, S., J. Trent Alexander, Katie Genadek, Ronald Goeken, Matthew B. Schroeder, and Matthew Sobek. (2010). Integrated Public Use Microdata Series: Version 5.0 [Machinereadable database].

Sims, D. P. (2011). Lifting All Boats? Finance Litigation, Education Resources, and Student Needs in the Post-Rose Era. Education Finance and Policy, 6(4), 455-485.

Solon, G. (2004). A Model of Intergenerational Mobility Variation over Time and Place. In M. Corak (Ed.), Generational income mobility in North America and Europe (pp. 38-47): Cambridge; New York and Melbourne:Cambridge University Press. 
Figure 1: County-Level Mobility Rates in the United States

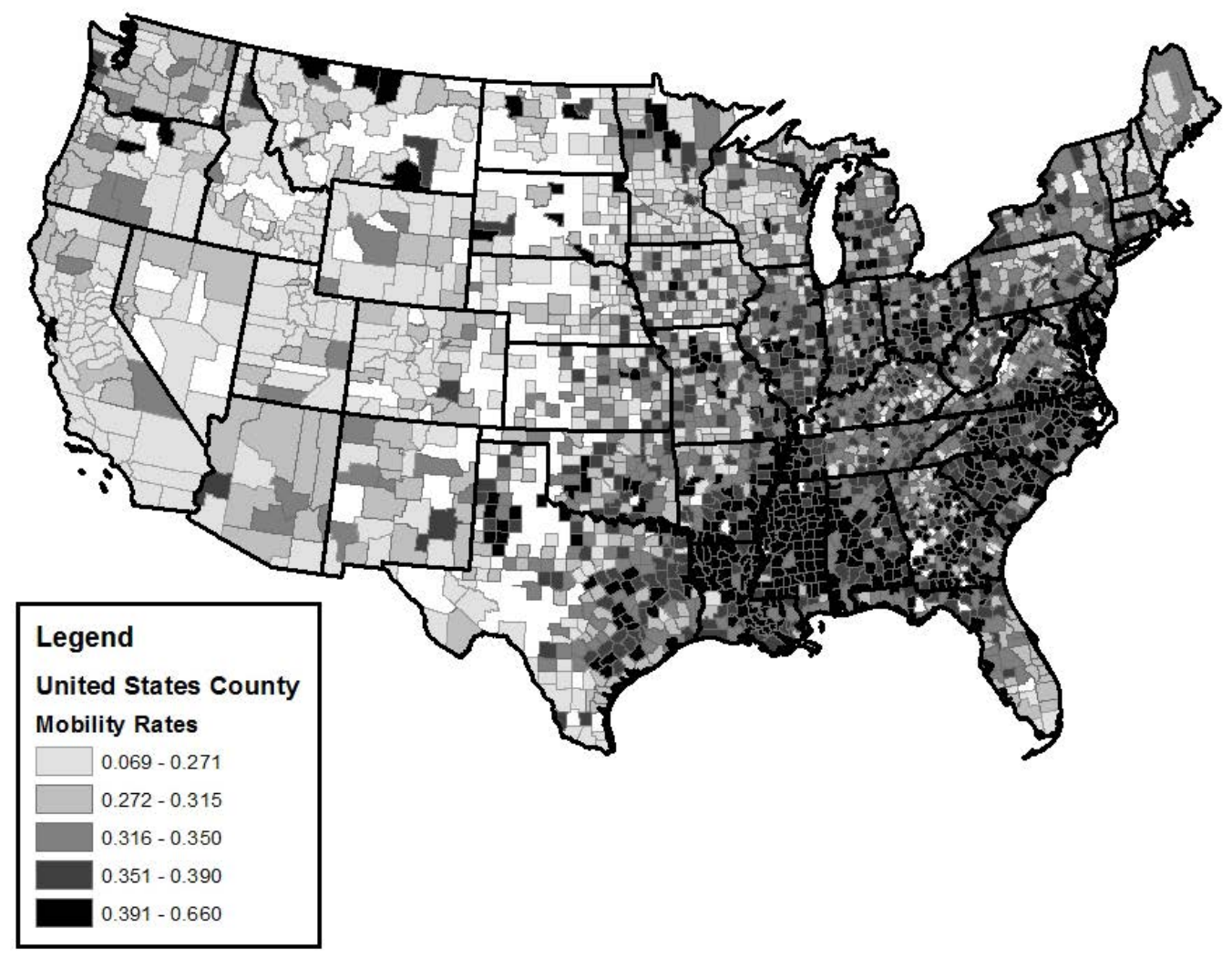

Figure 2: County-Level Mobility Rates Zoomed-In on Kentucky

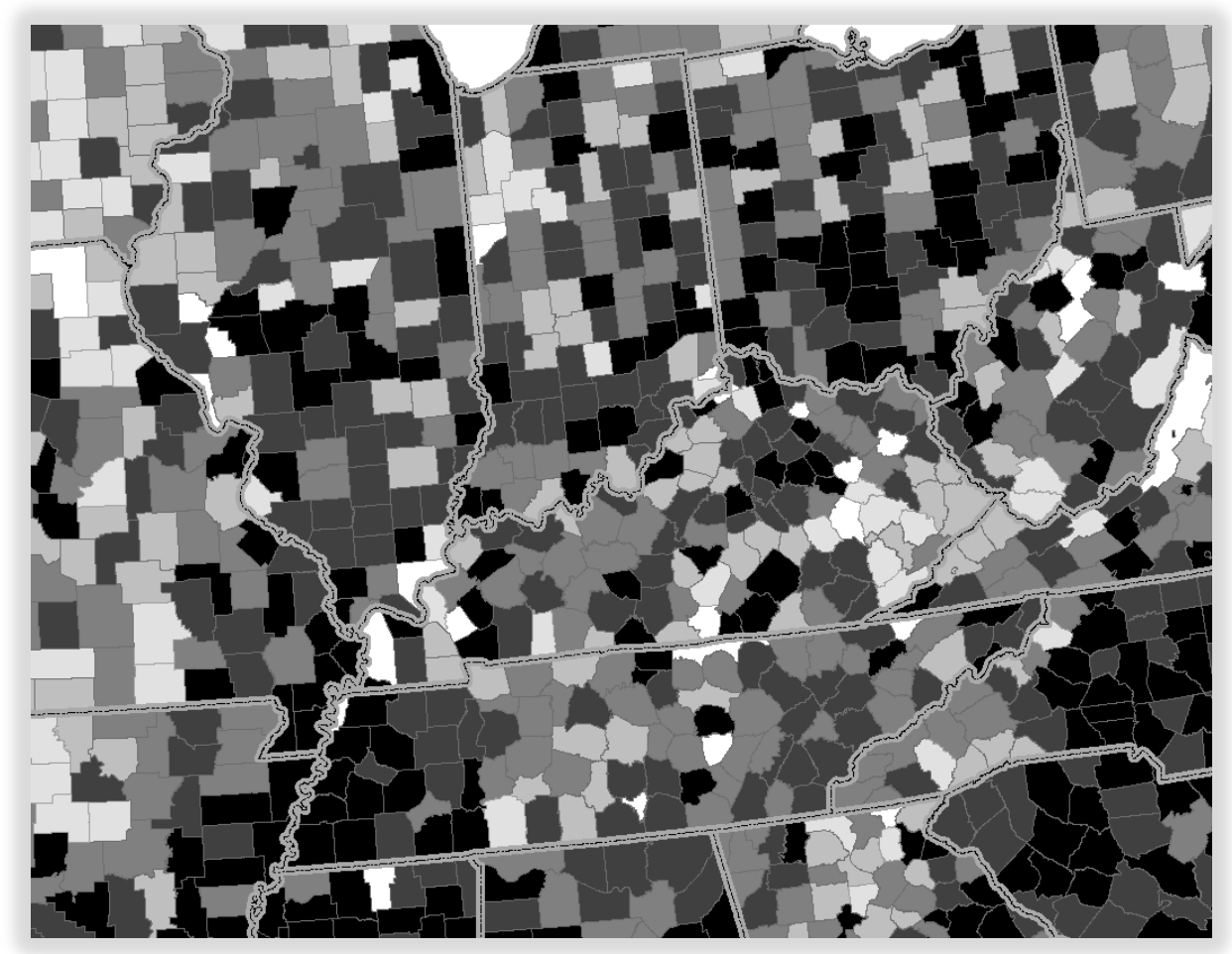


Figure 3: State Differences in the Levels of Non-Federal Education Spending

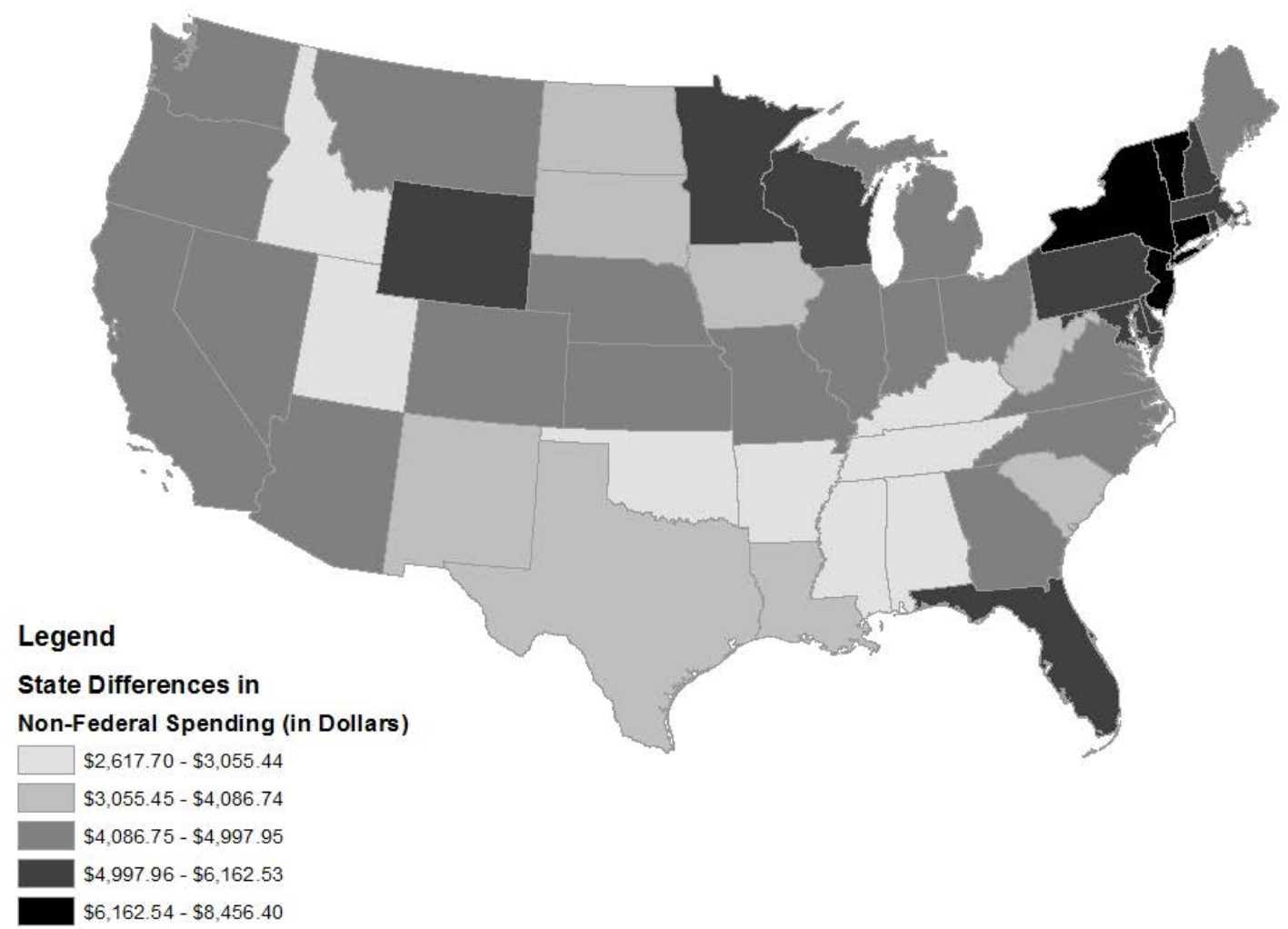

Figure 4: State Differences in Spending Progressivity Based on Free Lunch Quintiles

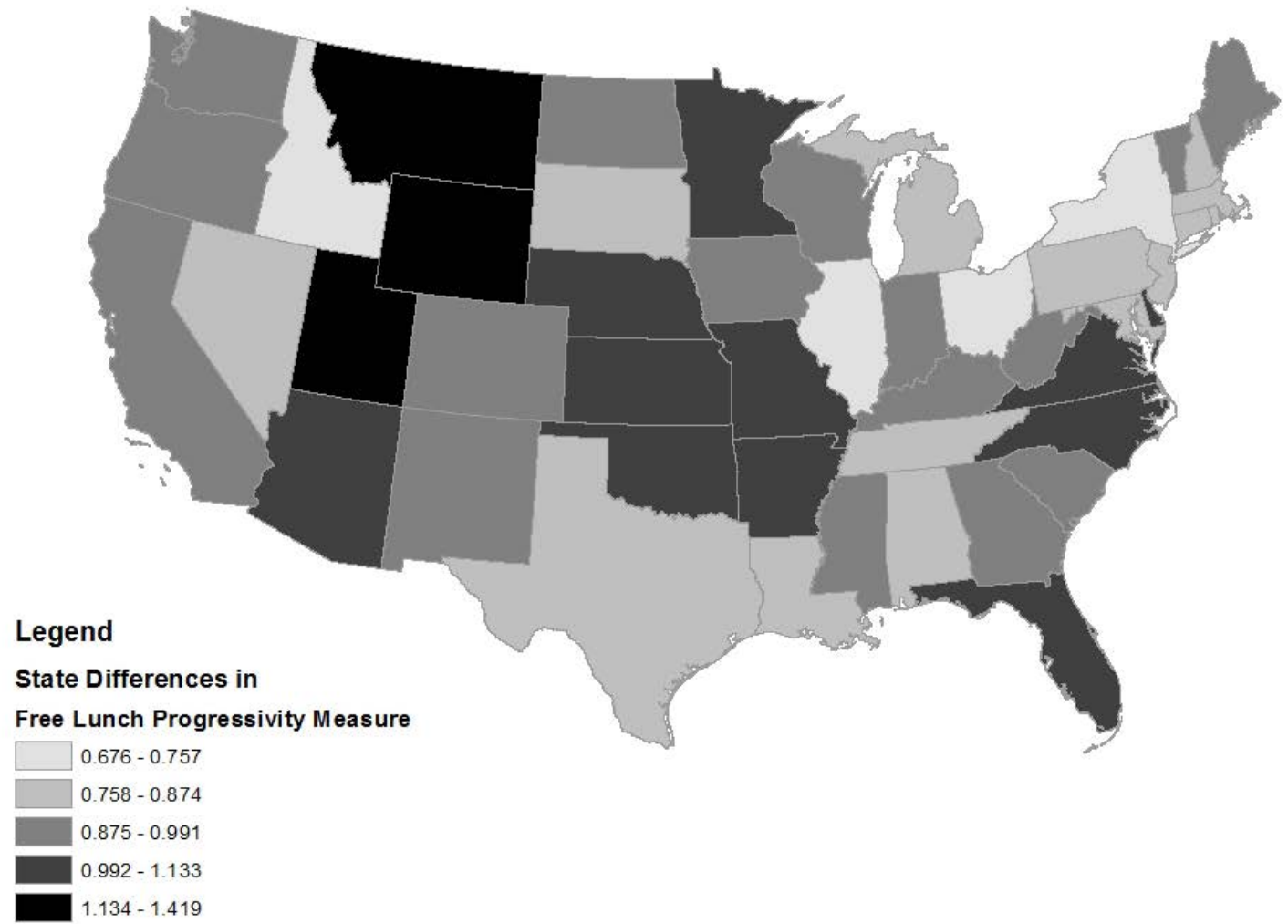


Figure 5: State Differences in Marginal Tax Rate for Middle Income Families

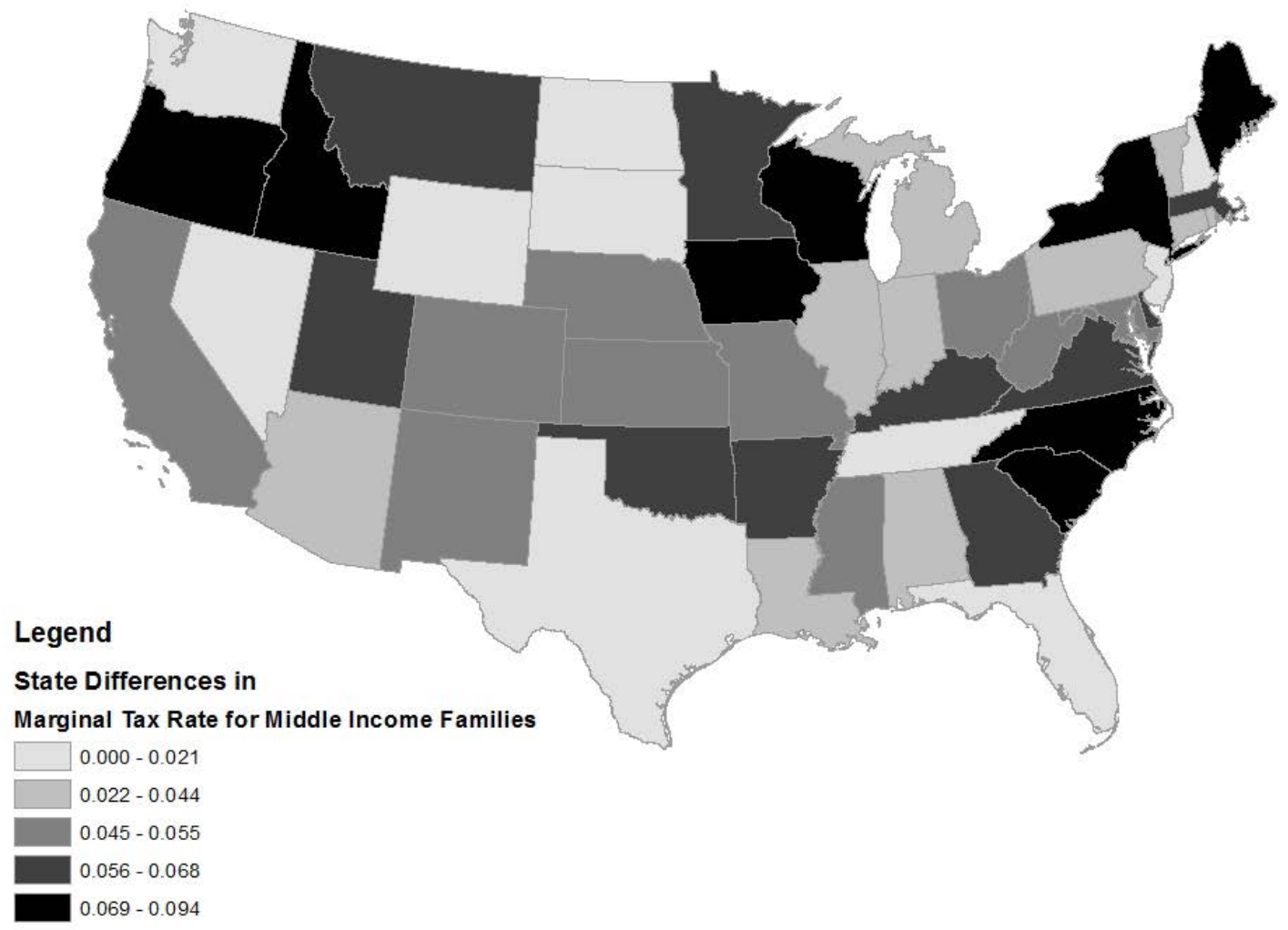

Figure 6: State Differences in Aid Available to the Families of Poor Children (CPS Data)

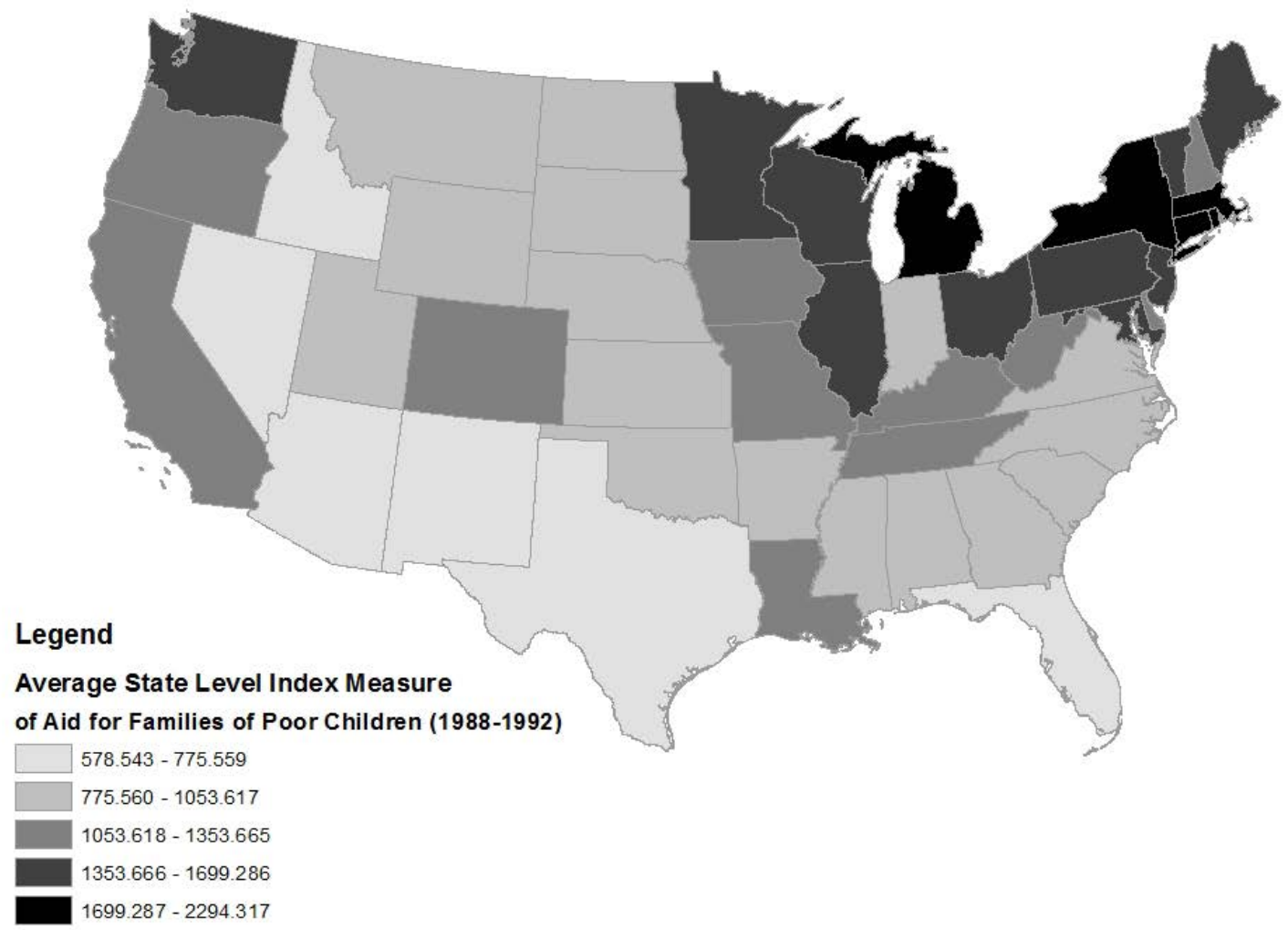


Figure 7: Border County Identification Strategy—Texas, Louisiana Close-Up

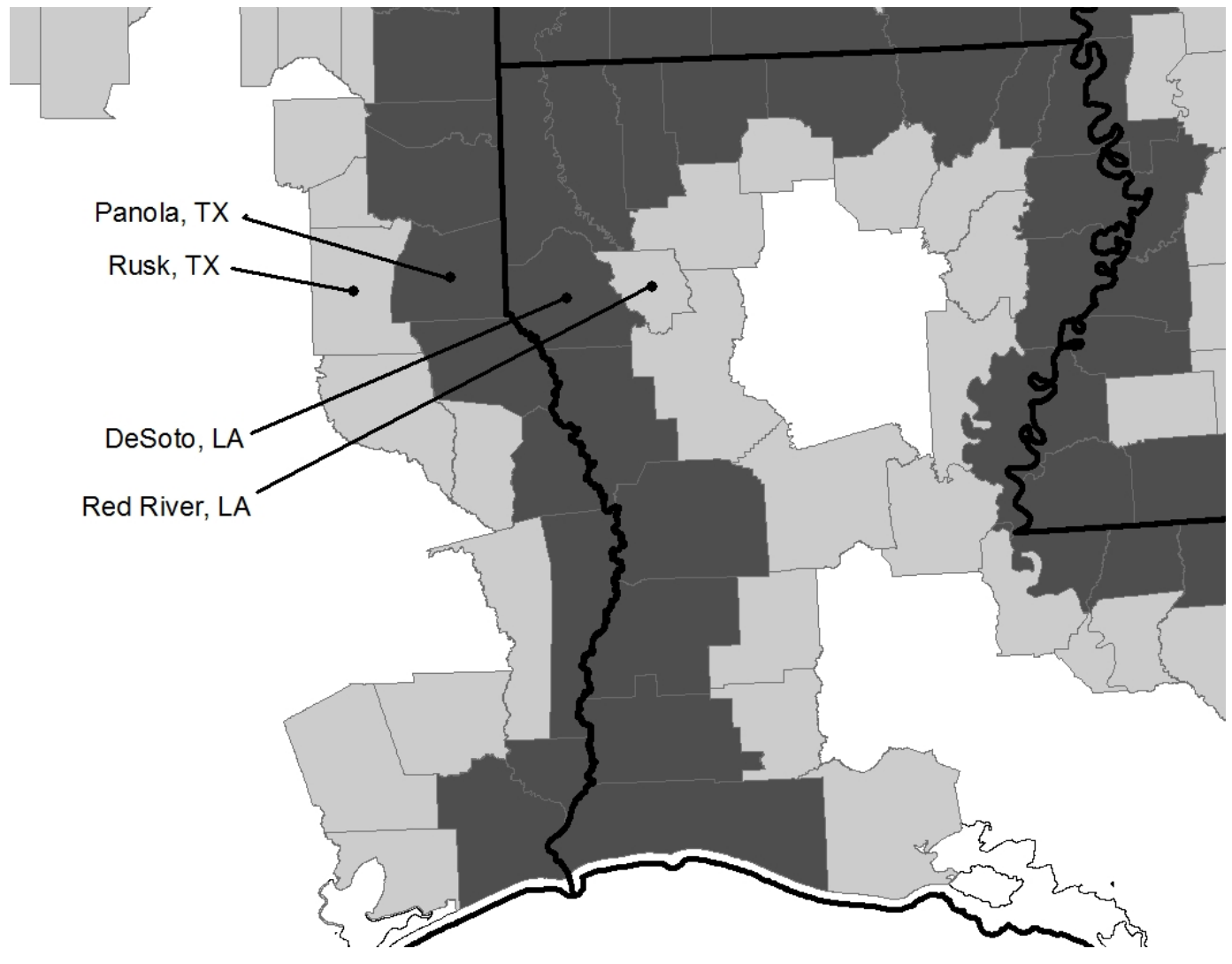

Figure 8: Analysis Sample

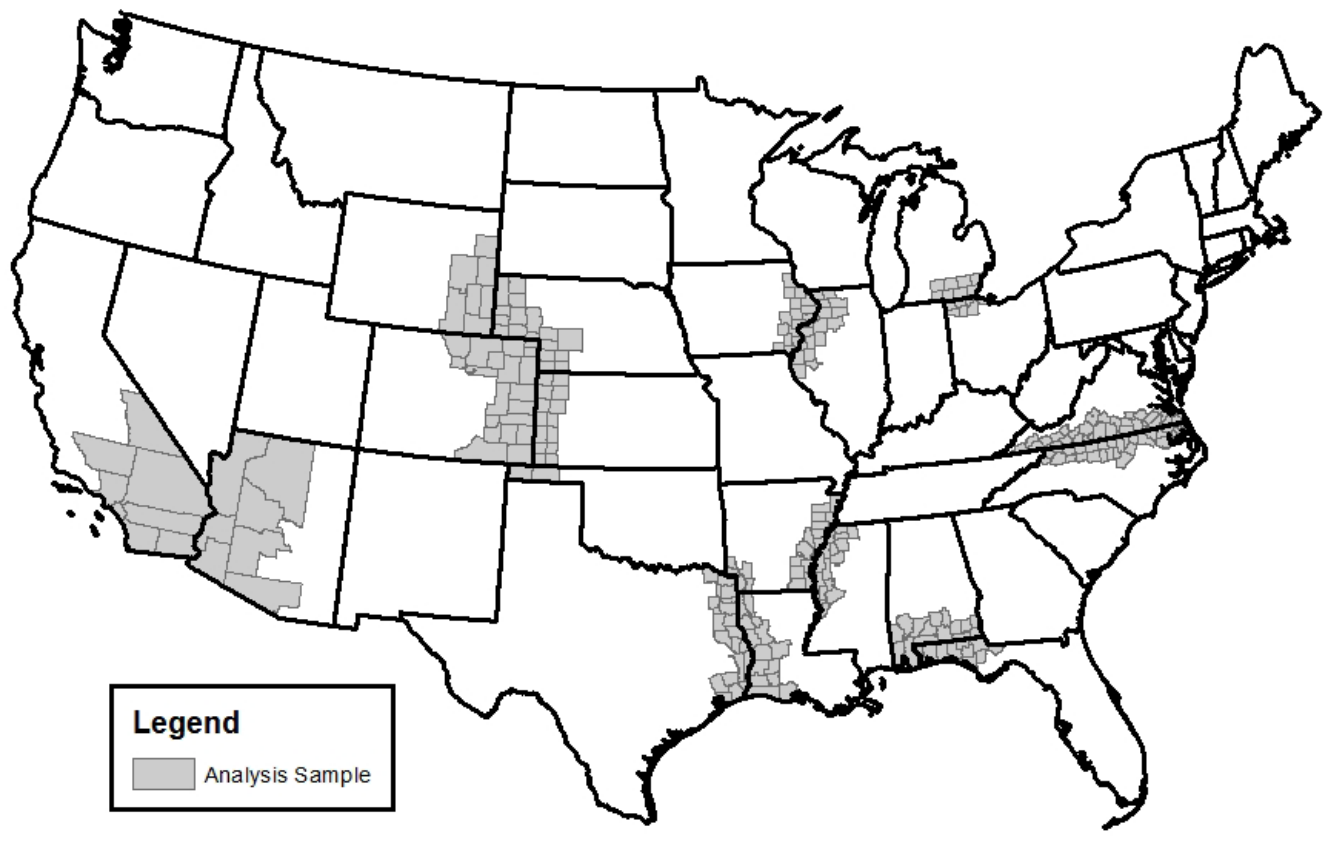


Figure 9: Fraction Residing in Birth State by Age

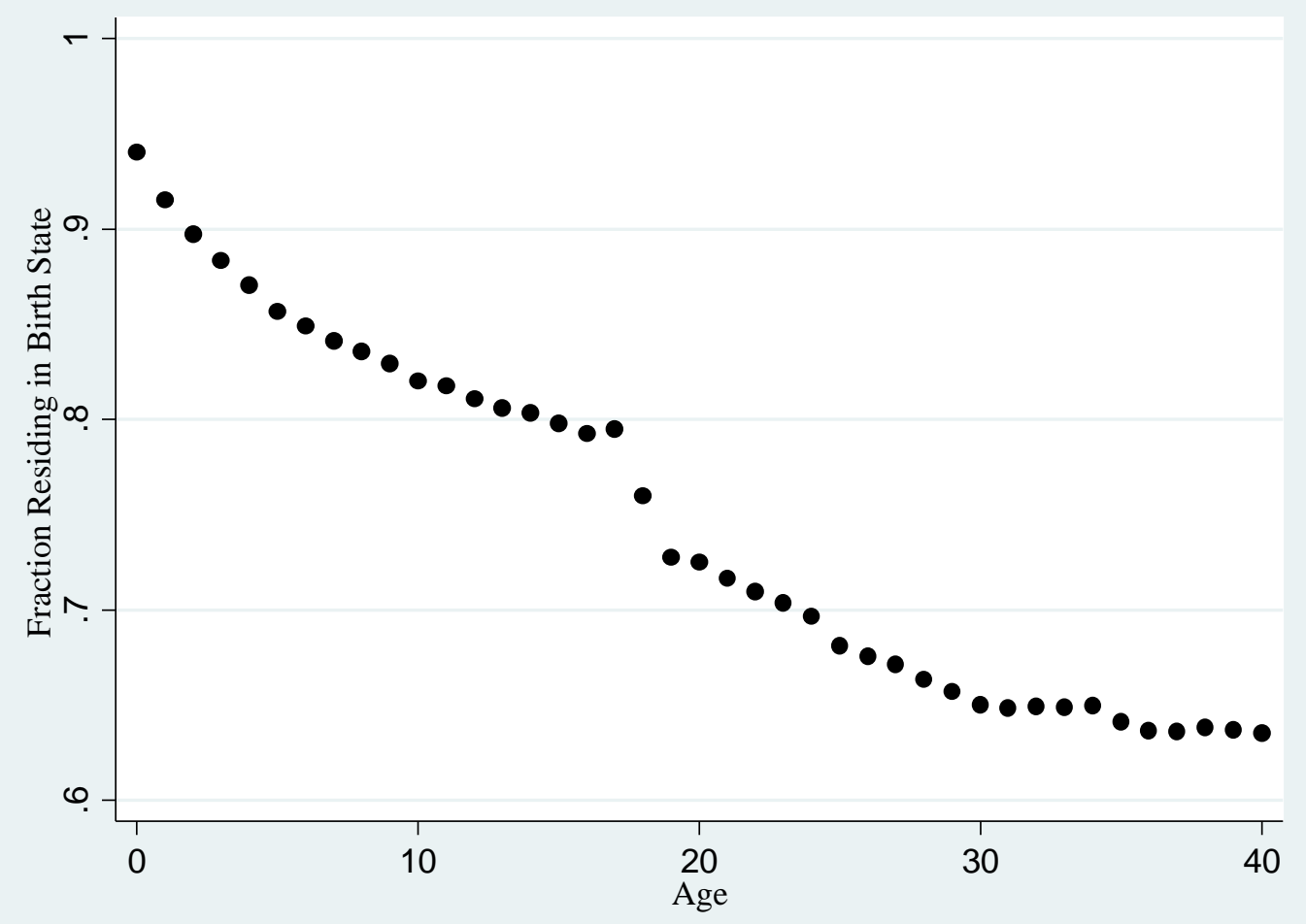


Table 1: Summary Statistics

\begin{tabular}{|c|c|c|}
\hline Variable & $\begin{array}{c}\text { County-Level } \\
\text { Summary Statistics }\end{array}$ & $\begin{array}{c}\text { State-Level } \\
\text { Summary Statistics }\end{array}$ \\
\hline Rank Correlation * 100 & $\begin{array}{c}33.11 \\
(7.16)\end{array}$ & $\begin{array}{l}32.26 \\
(4.78)\end{array}$ \\
\hline Fraction Teen Mothers & $\begin{array}{c}0.17 \\
(0.06)\end{array}$ & $\begin{array}{c}0.14 \\
(0.04)\end{array}$ \\
\hline Fraction Middle Class & $\begin{array}{c}0.55 \\
(0.09)\end{array}$ & $\begin{array}{c}0.52 \\
(0.05)\end{array}$ \\
\hline \multicolumn{3}{|l|}{ Parents’ Income } \\
\hline Gini Coefficient & $\begin{array}{c}0.38 \\
(0.09)\end{array}$ & $\begin{array}{c}0.43 \\
(0.08)\end{array}$ \\
\hline Income Share of Top 1 Percent & $\begin{array}{c}0.10 \\
(0.05)\end{array}$ & $\begin{array}{c}0.13 \\
(0.03)\end{array}$ \\
\hline Mean & $\begin{array}{l}\$ 67,346 \\
(24,421)\end{array}$ & $\begin{array}{l}\$ 85,284 \\
(15,648)\end{array}$ \\
\hline $25^{\text {th }}$ Percentile & $\begin{array}{l}\$ 30,397 \\
(10,453)\end{array}$ & $\begin{array}{l}\$ 35,070 \\
(7,925)\end{array}$ \\
\hline $50^{\text {th }}$ Percentile & $\begin{array}{l}\$ 52,974 \\
(15,805)\end{array}$ & $\begin{array}{l}\$ 62,245 \\
(11,571)\end{array}$ \\
\hline $75^{\text {th }}$ Percentile & $\begin{array}{l}\$ 81,610 \\
(20,510)\end{array}$ & $\begin{array}{l}\$ 96,513 \\
(14,338)\end{array}$ \\
\hline $90^{\text {th }}$ Percentile & $\begin{array}{l}\$ 115,807 \\
(33,866)\end{array}$ & $\begin{array}{l}\$ 143,025 \\
(23,406)\end{array}$ \\
\hline $99^{\text {th }}$ Percentile & $\begin{array}{l}\$ 322,165 \\
(208,310)\end{array}$ & $\begin{array}{l}\$ 490,903 \\
(148,516)\end{array}$ \\
\hline \multicolumn{3}{|l|}{ Children’s Income } \\
\hline Mean & $\begin{array}{c}\$ 45,803 \\
(8,777)\end{array}$ & $\begin{array}{l}\$ 48,184 \\
(6,437)\end{array}$ \\
\hline $25^{\text {th }}$ Percentile & $\begin{array}{l}\$ 16,435 \\
(5,509)\end{array}$ & $\begin{array}{l}\$ 16,486 \\
(3,967)\end{array}$ \\
\hline $50^{\text {th }}$ Percentile & $\begin{array}{l}\$ 35,654 \\
(8,748)\end{array}$ & $\begin{array}{l}\$ 36,435 \\
(6,358)\end{array}$ \\
\hline $75^{\text {th }}$ Percentile & $\begin{array}{l}\$ 63,791 \\
(11,674)\end{array}$ & $\begin{array}{l}\$ 66,186 \\
(8,745)\end{array}$ \\
\hline $90^{\text {th }}$ Percentile & $\begin{array}{l}\$ 94,776 \\
(13,399)\end{array}$ & $\begin{array}{l}\$ 99,904 \\
(10,637)\end{array}$ \\
\hline $99^{\text {th }}$ Percentile & $\begin{array}{l}\$ 190,236 \\
(39,269)\end{array}$ & $\begin{array}{l}\$ 210,134 \\
(26,412)\end{array}$ \\
\hline \multicolumn{3}{|l|}{ School Finance 1990-1995 } \\
\hline Per-Pupil Revenue (No Federal) & $\begin{array}{l}\$ 4,879 \\
(1,688)\end{array}$ & $\begin{array}{l}\$ 5,234 \\
(1,360)\end{array}$ \\
\hline Pupil-Teacher Ratio & $\begin{array}{l}16.09 \\
(2.59)\end{array}$ & $\begin{array}{l}17.17 \\
(2.08)\end{array}$ \\
\hline Progressivity of Funding & $\begin{array}{c}0.93 \\
(0.10)\end{array}$ & $\begin{array}{l}0.93 \\
(0.12)\end{array}$ \\
\hline
\end{tabular}




$\begin{array}{ccc}\text { Marginal Tax Rate (1985-2010) } & \\ \text { Income }=\$ 10,000 & 0.00 & -0.01 \\ & (0.02) & 0.02) \\ \text { Income }=\$ 50,000 & 0.04 & (0.03) \\ & (0.03) & 0.05 \\ \text { Income }=\$ 100,000 & 0.05 & (0.03) \\ \text { Real Per-Capita State Assistance to Households } & (0.03) & \$ 1,208 \\ \text { with Children } & \$ 1,114 & (409)\end{array}$

Notes: This table provides summary statistics for key variables used in the paper at the county and state level. Standard deviations are given in parentheses below means. 
Table 2: The Impact of Differences in State and Local Educational Per-Pupil Revenue on Differences in County Mobility Rates of Adjacent Counties in Different States

\begin{tabular}{lcccccc}
\hline & \multicolumn{7}{c}{ Specification } \\
\cline { 2 - 7 } Coefficient & $(1)$ & $(2)$ & $(3)$ & $(4)$ & $(5)$ & $(6)$ \\
\hline $\begin{array}{l}\text { Difference in 1990 State and } \\
\text { Local Revenue-State Average }\end{array}$ & -0.26 & -0.46 & -0.08 & - & -- & -- \\
$\begin{array}{l}\text { Difference in 1990 State and } \\
\text { Local Revenue-County }\end{array}$ & -- & -- & -- & $-0.64^{*}$ & -0.55 & -0.28 \\
$\begin{array}{l}\text { Average } \\
\text { Weight by Average Number of }\end{array}$ & No & Yes & No & No & Yes & No \\
Children in County Pair & No & No & Yes & No & No & Yes \\
Covariates & 0.001 & 0.001 & 0.252 & 0.011 & 0.011 & 0.254 \\
R-Squared & 1,930 & 1,930 & 1,930 & 1,930 & 1,930 & 1,930 \\
Observations & & & & & & \\
\hline
\end{tabular}

Notes: This table presents the coefficient estimates of equation (3) with the difference in perpupil state and local revenue (in thousands of dollars) as the independent variable of interest. The dependent variable is the difference in correlation of parents' income rank and children's income rank multiplied by 100. Included covariates are those listed in Table 8. The standard errors are corrected for two-way clustering at the state level for both comparison counties. * indicates statistical significance at the 10 percent and ${ }^{* *}$ indicates significance at the 5 percent level. 
Table 3: The Impact of Differences in Student Teacher Ratios on Differences in County Mobility Rates of Adjacent Counties in Different States

\begin{tabular}{|c|c|c|c|c|c|c|}
\hline \multirow[b]{2}{*}{ Coefficient } & \multicolumn{6}{|c|}{ Specification } \\
\hline & (1) & (2) & (3) & (4) & (5) & (6) \\
\hline $\begin{array}{l}\text { Difference in } 1990 \text { Student } \\
\text { Teacher Ratio-State Average }\end{array}$ & $\begin{array}{l}-0.12 \\
(0.19)\end{array}$ & $\begin{array}{l}-0.38 \\
(0.38)\end{array}$ & $\begin{array}{c}0.25 \\
(0.25)\end{array}$ & -- & -- & -- \\
\hline $\begin{array}{l}\text { Difference in } 1990 \text { Student } \\
\text { Teacher Ratio-County } \\
\text { Average }\end{array}$ & -- & -- & -- & $\begin{array}{l}-0.02 \\
(0.13)\end{array}$ & $\begin{array}{c}-0.34 \\
(0.35)\end{array}$ & $\begin{array}{c}0.15 \\
(0.17)\end{array}$ \\
\hline $\begin{array}{l}\text { Weight by Average Number of } \\
\text { Children in County Pair }\end{array}$ & No & Yes & No & No & Yes & No \\
\hline Covariates & No & No & Yes & No & No & Yes \\
\hline R-Squared & 0.001 & 0.014 & 0.255 & 0.000 & 0.017 & 0.254 \\
\hline Observations & 1,930 & 1,930 & 1,930 & 1,930 & 1,930 & 1,930 \\
\hline
\end{tabular}

Notes: This table presents the coefficient estimates of equation (2) with the difference in student teacher ratios as the independent variable of interest. The dependent variable is the difference in correlation of parents' income rank and children's income rank multiplied by 100 . Included covariates are those listed in Table 8. The standard errors are corrected for two-way clustering at the state level for both comparison counties. * indicates statistical significance at the 10 percent and $* *$ indicates significance at the 5 percent level.

Table 4: The Impact of Differences in Progressivity of School Funding on Differences in County Mobility Rates of Adjacent Counties in Different States

\begin{tabular}{lccc}
\hline & \multicolumn{3}{c}{ Specification } \\
\cline { 2 - 4 } Coefficient & $(1)$ & $(2)$ & $(3)$ \\
\hline Difference in 1990 Progressivity of & $-2.98^{*}$ & 0.88 & 1.22 \\
School Funding & $(1.59)$ & $(3.44)$ & $(2.82)$ \\
Weight by Average Number of & No & Yes & No \\
Children in County Pair & No & No & Yes \\
Covariates & 0.004 & 0.000 & 0.251 \\
R-Squared & 1,924 & 1,924 & 1,924 \\
Observations
\end{tabular}

Notes: This table presents the coefficient estimates of equation (3) with the difference in progressivity of school funding as the independent variable of interest. The dependent variable is the difference in correlation of parents' income rank and children's income rank multiplied by 100. The measure of progressivity is derived by dividing the funding of the lowest free-lunch quintile of counties by the revenue of the highest free-lunch quintile of counties. Included covariates are those listed in Table 8. The standard errors are corrected for two-way clustering at the state level for both comparison counties. * indicates statistical significance at the 10 percent and $* *$ indicates significance at the 5 percent level. 
Table 5: The Impact of Differences in Marginal Tax Rates on Differences in County Mobility Rates of Adjacent Counties in Different States

\begin{tabular}{|c|c|c|c|c|c|c|}
\hline \multirow[b]{2}{*}{ Coefficient } & \multicolumn{6}{|c|}{ Specification } \\
\hline & (1) & $(2)$ & (3) & (4) & (5) & (6) \\
\hline $\begin{array}{l}\text { Difference in Marginal Tax } \\
\text { Rates- at } \$ 10,000 \text { (2005 Dollars) } \\
\text { Adjusted Gross Income }\end{array}$ & $\begin{array}{l}-17.10 \\
(12.29)\end{array}$ & -- & -- & $\begin{array}{l}-22.92 * \\
(13.60)\end{array}$ & $\begin{array}{l}-12.26 \\
(11.98)\end{array}$ & $\begin{array}{l}-17.98 \\
(11.12)\end{array}$ \\
\hline $\begin{array}{l}\text { Difference in Marginal Tax } \\
\text { Rates_ at } \$ 50,000 \text { (2005 Dollars) } \\
\text { Adjusted Gross Income }\end{array}$ & -- & $\begin{array}{c}-6.31 \\
(11.63)\end{array}$ & -- & $\begin{array}{c}22.99 \\
(30.57)\end{array}$ & $\begin{array}{c}55.05 \\
(48.34)\end{array}$ & $\begin{array}{c}24.14 \\
(26.43)\end{array}$ \\
\hline $\begin{array}{l}\text { Difference in Marginal Tax } \\
\text { Rates-at } \$ 100,000 \text { (2005 Dollars) } \\
\text { Adjusted Gross Income }\end{array}$ & -- & -- & $\begin{array}{c}-7.77 \\
(10.83)\end{array}$ & $\begin{array}{l}-31.48 \\
(29.78)\end{array}$ & $\begin{array}{l}-46.06 \\
(44.81)\end{array}$ & $\begin{array}{l}-33.13 \\
(24.84)\end{array}$ \\
\hline $\begin{array}{l}\text { Weight by Average Number of } \\
\text { Children in County Pair }\end{array}$ & No & No & No & No & Yes & No \\
\hline Covariates & No & No & No & No & No & Yes \\
\hline R-Squared & 0.000 & 0.001 & 0.002 & 0.009 & 0.019 & 0.221 \\
\hline Observations & 1,944 & 1,944 & 1,944 & 1,944 & 1,944 & 1,944 \\
\hline
\end{tabular}

Notes: This table shows the results of estimating equation (3) using the differences in TAXSIM generated marginal tax rates between adjacent states as the primary independent variable of interest. The dependent variable is the difference in correlation of parents' income rank and children's income rank multiplied by 100 . Included covariates are those listed in Table 8 . The standard errors are corrected for two-way clustering at the state level for both comparison counties. * indicates statistical significance at the 10 percent and $* *$ indicates significance at the 5 percent level. 
Table 6: The Impact of Differences in Average Real Per-Capita Public Assistance for Households with Children on Differences in County Mobility Rates of Adjacent Counties in Different States

\begin{tabular}{lccc}
\hline & \multicolumn{3}{c}{ Specification } \\
\cline { 2 - 4 } Coefficient & $(1)$ & $(2)$ & $(3)$ \\
\hline Difference in Real Per-Capita Public & $2.21^{* *}$ & 1.64 & $1.41^{*}$ \\
Assistance (\$1000s) & $(1.06)$ & $(1.54)$ & $(0.72)$ \\
Weight by Average Number of & No & Yes & No \\
Children in County Pair & No & No & Yes \\
Covariates & 0.011 & 0.010 & 0.219 \\
R-Squared & 1,944 & 1,944 & 1,944 \\
Observations & &
\end{tabular}

Notes: This table presents the coefficient estimates of equation (3) with the difference in average real per-capita public assistance for households with children as the independent variable of interest. The dependent variable is the difference in correlation of parents' income rank and children's income rank multiplied by 100 . Included covariates are those listed in Table 8 . The standard errors are cluster corrected at the state-border level. * indicates statistical significance at the 10 percent and $* *$ indicates significance at the 5 percent level.

Table 7: The Impact of Being in a Different State on the Variance in the Difference of Intergenerational Mobility between Adjacent Counties

\begin{tabular}{lccc}
\hline & \multicolumn{3}{c}{ Specification } \\
\cline { 2 - 4 } & $(1)$ & $(2)$ & $(3)$ \\
\hline \multirow{2}{*}{ Constant } & $47.86^{* *}$ & $36.34 * *$ & $34.79^{* *}$ \\
& $(2.70)$ & $(3.93)$ & $(2.32)$ \\
Different State & 2.13 & 2.68 & 3.49 \\
Weight by Average Number of Children in & $(3.64)$ & $(6.37)$ & $(2.79)$ \\
County Pair & No & Yes & No \\
Covariates in First Stage & No & No & Yes \\
R-Squared & 0.00 & 0.00 & 0.00 \\
Observations & 14,252 & 14,252 & 14,252 \\
\hline
\end{tabular}

Notes: This table reports the results of our second stage regression (see equation 8 and discussion for details). Column (1) contains results from a model with no covariates. The constant can be interpreted as an estimate of the variance in the difference in mobility rates across adjacent counties within the same state. Column (2) weights by average number of children in county pair. Column (3) does not use the weights but includes covariates in the first stage (see equations 4 and 6 for more details). The standard errors are corrected for two-way clustering at the state level for both comparison counties. * indicates statistical significance at the 10 percent and ** indicates significance at the 5 percent level. 
Table 8: Regression of Difference in County Mobility Rates on Differences in Observed Characteristics

\begin{tabular}{|c|c|}
\hline Variable (in Differences) & Coefficient \\
\hline Fraction Births to Teens & $\begin{array}{c}43.78^{* *} \\
(5.52)\end{array}$ \\
\hline Fraction of Families in Middle Class & $\begin{array}{c}-8.09 * * \\
(3.18)\end{array}$ \\
\hline \multicolumn{2}{|c|}{$\begin{array}{l}\text { County Family Income Statistics of Parent } \\
\text { Cohort }(\$ 10,000)\end{array}$} \\
\hline Gini Coefficient & $\begin{array}{c}10.31^{* *} \\
(4.41)\end{array}$ \\
\hline Income Share of Top 1 Percent & $\begin{array}{l}-8.93 \\
(5.87)\end{array}$ \\
\hline Mean & $\begin{array}{c}0.11 \\
(0.22)\end{array}$ \\
\hline $25^{\text {th }}$ Percentile & $\begin{array}{c}0.37 \\
(0.54)\end{array}$ \\
\hline $50^{\text {th }}$ Percentile & $\begin{array}{c}0.07 \\
(0.53)\end{array}$ \\
\hline $75^{\text {th }}$ Percentile & $\begin{array}{l}-0.26 \\
(0.43)\end{array}$ \\
\hline $90^{\text {th }}$ Percentile & $\begin{array}{c}-0.33^{* *} \\
(0.16)\end{array}$ \\
\hline $99^{\text {th }}$ Percentile & $\begin{array}{l}-0.01 \\
(0.01)\end{array}$ \\
\hline \multicolumn{2}{|c|}{$\begin{array}{l}\text { County Family Income Statistics of Child } \\
\text { Cohort }(\$ 10,000)\end{array}$} \\
\hline Mean & $\begin{array}{l}-0.07 \\
(0.53)\end{array}$ \\
\hline $25^{\text {th }}$ Percentile & $\begin{array}{l}-6.11^{* *} \\
(1.03)\end{array}$ \\
\hline $50^{\text {th }}$ Percentile & $\begin{array}{l}-2.35^{* *} \\
(1.10)\end{array}$ \\
\hline $75^{\text {th }}$ Percentile & $\begin{array}{l}1.65^{* *} \\
(0.42)\end{array}$ \\
\hline $90^{\text {th }}$ Percentile & $\begin{array}{c}2.36^{* *} \\
(0.44)\end{array}$ \\
\hline $99^{\text {th }}$ Percentile & $\begin{array}{l}0.12^{*} \\
(0.06)\end{array}$ \\
\hline $\begin{array}{l}\text { R-Squared } \\
\text { Observations }\end{array}$ & $\begin{array}{c}0.27 \\
14252\end{array}$ \\
\hline
\end{tabular}

Notes: This table reports the results of a regression of the difference in county mobility rates on differences in observed characteristics. The standard errors are corrected for two-way clustering at the state level for both comparison counties. * indicates statistical significance at the 10 percent and $* *$ indicates significance at the 5 percent level. 
Table 9: The Differences in Mobility of Adjacent Counties in States with Large Average Mobility Differences

\begin{tabular}{|c|c|c|c|c|c|c|}
\hline \multirow[b]{2}{*}{ Coefficient } & \multicolumn{6}{|c|}{ Specification } \\
\hline & (1) & (2) & (3) & (4) & (5) & (6) \\
\hline Mobile State & $\begin{array}{c}-1.47^{* *} \\
(0.62)\end{array}$ & $\begin{array}{l}-0.52 \\
(1.22)\end{array}$ & $\begin{array}{l}-0.42 \\
(1.28)\end{array}$ & $\begin{array}{c}-3.91 * * \\
(0.86)\end{array}$ & $\begin{array}{l}-1.35 \\
(1.17)\end{array}$ & $\begin{array}{l}-0.68 \\
(1.57)\end{array}$ \\
\hline Index & -- & $\begin{array}{l}-0.43 \\
(0.54)\end{array}$ & $\begin{array}{l}-0.41 \\
(0.51)\end{array}$ & -- & $\begin{array}{r}-1.08^{*} \\
(0.59)\end{array}$ & $\begin{array}{l}-0.91 \\
(0.73)\end{array}$ \\
\hline State-Pair Fixed Effects & Yes & Yes & Yes & Yes & Yes & Yes \\
\hline Covariates & No & No & Yes & No & No & Yes \\
\hline $\begin{array}{l}\text { Weight by Number of } \\
\text { Children }\end{array}$ & No & No & No & Yes & Yes & Yes \\
\hline R-Squared & 0.537 & 0.538 & 0.718 & 0.834 & 0.839 & 0.919 \\
\hline Observations & 264 & 264 & 264 & 264 & 264 & 264 \\
\hline
\end{tabular}

Notes: This table reports our key results for adjacent counties in states with large average mobility differences. Included covariates are those listed in Table 8 . The standard errors are cluster corrected at the state-border level. * indicates statistical significance at the 10 percent and $* *$ indicates significance at the 5 percent level. 
Table 10: The Relationship of Differences in State and Local Policy and Differences in Observed Characteristics of Adjacent Counties in Different States

\begin{tabular}{|c|c|c|c|c|c|}
\hline Variable & $\begin{array}{l}\text { Per-Pupil } \\
\text { Revenues }\end{array}$ & $\begin{array}{c}\text { Student } \\
\text { Teacher } \\
\text { Ratio }\end{array}$ & $\begin{array}{l}\text { Education } \\
\text { Funding } \\
\text { Progressivity }\end{array}$ & $\begin{array}{l}\text { Marginal } \\
\text { Tax Rates }\end{array}$ & $\begin{array}{c}\text { Social Safety } \\
\text { Net }\end{array}$ \\
\hline & $(1)$ & $(2)$ & (3) & $(4)$ & $(5)$ \\
\hline Mobility Index & 0.09 & 0.03 & 0.02 & 0.72 & 0.52 \\
\hline Fraction Births to Teens & 0.05 & 0.08 & 0.12 & 0.82 & 0.03 \\
\hline Fraction of Families in Middle Class & 0.91 & 0.13 & 0.61 & 0.94 & 0.52 \\
\hline \multicolumn{6}{|l|}{$\begin{array}{l}\text { County Family Income Statistics of } \\
\text { Parent Cohort }\end{array}$} \\
\hline Gini Coefficient & 0.84 & 0.04 & 0.77 & 0.81 & 0.78 \\
\hline Income Share of Top 1 Percent & 0.43 & 0.06 & 0.56 & 0.19 & 0.42 \\
\hline County Mean & 0.33 & 0.17 & 0.45 & 0.05 & 0.83 \\
\hline $25^{\text {th }}$ Percentile & 0.28 & 0.97 & 0.86 & 0.00 & 0.08 \\
\hline $50^{\text {th }}$ Percentile & 0.39 & 0.89 & 0.72 & 0.00 & 0.21 \\
\hline $75^{\text {th }}$ Percentile & 0.63 & 1.00 & 0.84 & 0.01 & 0.49 \\
\hline $90^{\text {th }}$ Percentile & 0.67 & 0.66 & 0.70 & 0.00 & 0.90 \\
\hline 99 $9^{\text {th }}$ Percentile & 0.55 & 0.21 & 0.56 & 0.00 & 0.75 \\
\hline \multicolumn{6}{|l|}{$\begin{array}{l}\text { County Family Income Statistics of } \\
\text { Child Cohort }\end{array}$} \\
\hline County Mean & 0.03 & 0.73 & 0.48 & 0.36 & 0.33 \\
\hline $25^{\text {th }}$ Percentile & 0.06 & 0.18 & 0.12 & 0.84 & 0.75 \\
\hline $50^{\text {th }}$ Percentile & 0.02 & 0.25 & 0.19 & 0.66 & 0.59 \\
\hline $75^{\text {th }}$ Percentile & 0.02 & 0.80 & 0.93 & 0.31 & 0.23 \\
\hline $90^{\text {th }}$ Percentile & 0.04 & 0.48 & 0.69 & 0.22 & 0.11 \\
\hline $99^{\text {th }}$ Percentile & 0.23 & 0.30 & 0.75 & 0.56 & 0.31 \\
\hline
\end{tabular}

Notes: This table reports p-values on the coefficient of the difference in the given state policy measure in an unweighted regression of the observed covariate on the difference in state policy. The standard errors are corrected for two-way clustering at the state level for both comparison counties with one exception. In the second column (Student Teacher Ratio), in the case of the $99^{\text {th }}$ percentile of family income in the parent cohort, two-way clustering did not produce a valid covariance matrix so the standard errors are clustered the state border level. 
Table 11: Testing Whether Observed County Characteristics Differ More across State Borders than County Borders

\begin{tabular}{lcc}
\hline \multicolumn{1}{c}{ Variable } & All states & $\begin{array}{c}\text { High Contrast } \\
\text { States }\end{array}$ \\
\hline & & $(1)$ \\
\hline Mobility Index & 0.10 & 0.21 \\
Fraction Births to Teens & 0.69 & 0.34 \\
Fraction of Families in Middle Class & 0.98 & 0.44 \\
County Family Income Statistics of Parent Cohort & & \\
Gini Coefficient & 0.12 & 0.86 \\
Income Share of Top 1 Percent & 0.02 & 0.88 \\
County Mean & 0.50 & 0.72 \\
25 & 0.50 & 0.42 \\
$50^{\text {th }}$ Percentile & 0.33 & 0.58 \\
$75^{\text {th }}$ Percentile & 0.68 & 0.60 \\
$90^{\text {th }}$ Percentile & 0.57 & 0.77 \\
$99^{\text {th }}$ Percentile & 0.47 & 0.98 \\
County Family Income Statistics of Child Cohort & & \\
County Mean & 0.19 & 0.28 \\
$25^{\text {th }}$ Percentile & 0.12 & 0.25 \\
$50^{\text {th }}$ Percentile & 0.10 & 0.25 \\
$75^{\text {th }}$ Percentile & 0.06 & 0.31 \\
$90^{\text {th }}$ Percentile & 0.06 & 0.48 \\
$99^{\text {th }}$ Percentile & 0.99 & 0.44 \\
\hline
\end{tabular}

Notes: Column (1) of this table reports p-values on the coefficient of a different state dummy variable in an unweighted regression of squared differences of observed characteristics on a constant and a different state dummy variable. Column (2) relies on only the states which are part of a pair across which the mobility contrast is greatest, as shown in Figure 4 . The p-values correspond to the effect of being in the more mobile state as discussed in equation (9). In the first column, the standard errors are corrected for two-way clustering at the state level for both comparison counties with one exception. In the case of the $25^{\text {th }}$ percentile of family income in the child cohort, two-way clustering did not produce a valid covariance matrix so the standard errors are clustered the state border level. In the second column, the standard errors are corrected at the state level. 
Table 12: Summary Statistics of IRS County-to-County Migration Data for Analysis Sample

\begin{tabular}{|c|c|c|c|c|c|c|c|}
\hline Variable & Obs & Mean & $\begin{array}{l}\text { Std. } \\
\text { Dev. }\end{array}$ & Min & Max & $\begin{array}{l}\text { Lower C.I. } \\
\text { bound (95\%) }\end{array}$ & $\begin{array}{c}\text { Upper C.I. } \\
\text { bound } \\
(95 \%)\end{array}$ \\
\hline \multicolumn{8}{|l|}{ A. All border counties } \\
\hline Total Migrant Inflows & 125 & 4769 & 15055 & 29 & 122955 & & \\
\hline Total Migrant Outflows & 125 & 4116 & 11353 & 51 & 89353 & & \\
\hline Total Migrant, Same State, Border County Inflows & 125 & 705 & 2522 & 0 & 21192 & & \\
\hline Total Migrant, Adjacent State Border, County Inflows & 125 & 170 & 344 & 0 & 2006 & & \\
\hline Percent Migrant Inflows & 125 & 0.0672 & 0.0292 & 0.0349 & 0.2202 & & \\
\hline Percent Migrant Outflows & 125 & 0.0667 & 0.0250 & 0.0359 & 0.2545 & & \\
\hline $\begin{array}{l}\text { Percent Migrant, Same State, Border County Inflows } \\
\text { Percent Migrant, Adiacent State, Border County }\end{array}$ & 125 & 0.0096 & 0.0103 & 0.0000 & 0.0499 & & \\
\hline Inflows & 125 & 0.0037 & 0.0069 & 0.0000 & 0.0473 & & \\
\hline \multicolumn{8}{|l|}{ B. Counties by state mobility level } \\
\hline $\begin{array}{l}\text { Percent Migrant, Adjacent State, Border County } \\
\text { Inflows (Low Mobility) }\end{array}$ & 69 & 0.0046 & 0.0088 & & & 0.0025 & 0.0068 \\
\hline $\begin{array}{l}\text { Percent Migrant, Adjacent State, Border County } \\
\text { Inflows (High Mobility) }\end{array}$ & 56 & 0.0025 & 0.0029 & & & 0.0017 & 0.0033 \\
\hline
\end{tabular}

